
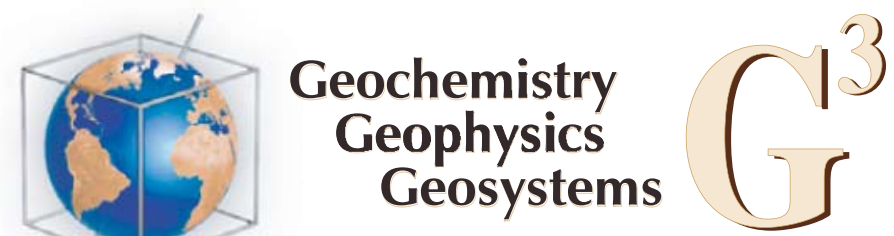

\title{
A survey of volcanic deformation on Java using ALOS PALSAR interferometric time series
}

\section{Belle Philibosian}

Tectonics Observatory, Division of Geological and Planetary Sciences, California Institute of Technology, MC 100-23 Caltech, Pasadena, California 91125, USA (belle@gps.caltech.edu)

\section{Mark Simons \\ Seismological Laboratory, Division of Geological and Planetary Sciences, California Institute of Technology, MC 252-21 Caltech, Pasadena, California 91125, USA (simons@caltech.edu)}

[1] Of the hundreds of volcanic centers throughout the Indonesian archipelago, few are adequately monitored for pre-eruptive activity due to socioeconomic and logistical barriers, with the result that volcanic hazards in the region are not well quantified. The advent of satellite-borne L-band synthetic aperture radar provides an opportunity for detection and measurement of volcanic deformation over broad regions in heavily vegetated tropical island arcs. We use data from the PALSAR instrument on the Japanese ALOS satellite to conduct a comprehensive survey of volcanic deformation on the Indonesian island of Java, over a time period of two years (2007-2008). To obtain the most complete, temporally continuous record of ground deformation, we use a temporally overlapping set of short-time-interval radar image pairs to produce a deformation time series. Consistent with previous results from other regions, our survey suggests that volcanoes experiencing small eruptions are typically fed by magma bodies too small and/or too shallow or deep to produce a recognizable InSAR signal. However, we identified a deformation event at Lamongan volcano which is likely linked to a magmatic intrusion at several kilometers' depth, and a second one at Slamet volcano at a shallower depth that may have been related to a subsequent eruption. This initial test of a broad application of L-band data allowed us to better define the satellite imaging criteria required for successful observation, as well as developing a useful methodology for monitoring deformation over a wide region.

Components: 8200 words, 18 figures, 2 tables.

Keywords: InSAR; Java; L-band; PALSAR; deformation; volcanoes.

Index Terms: 1240 Geodesy and Gravity: Satellite geodesy: results (6929, 7215, 7230, 7240); 8485 Volcanology: Remote sensing of volcanoes (4337).

Received 8 July 2011; Revised 20 September 2011; Accepted 30 September 2011; Published 8 November 2011.

Philibosian, B., and M. Simons (2011), A survey of volcanic deformation on Java using ALOS PALSAR interferometric time series, Geochem. Geophys. Geosyst., 12, Q11004, doi:10.1029/2011GC003775.

\section{Introduction}

[2] In the past two decades, radar interferometry has become a widely used geodetic tool for detecting and measuring distributed ground deformation [e.g., Massonnet and Feigl, 1998; Bürgmann et al., 2000;
Hanssen, 2001; Simons and Rosen, 2007]. Interferometric synthetic aperture radar (InSAR) observations have revolutionized our ability to measure seismic, volcanic, and hydrologic deformation. Pritchard and Simons [2004a] demonstrated that InSAR has great potential as a tool to survey large areas of deformation in volcanic arcs. However, 


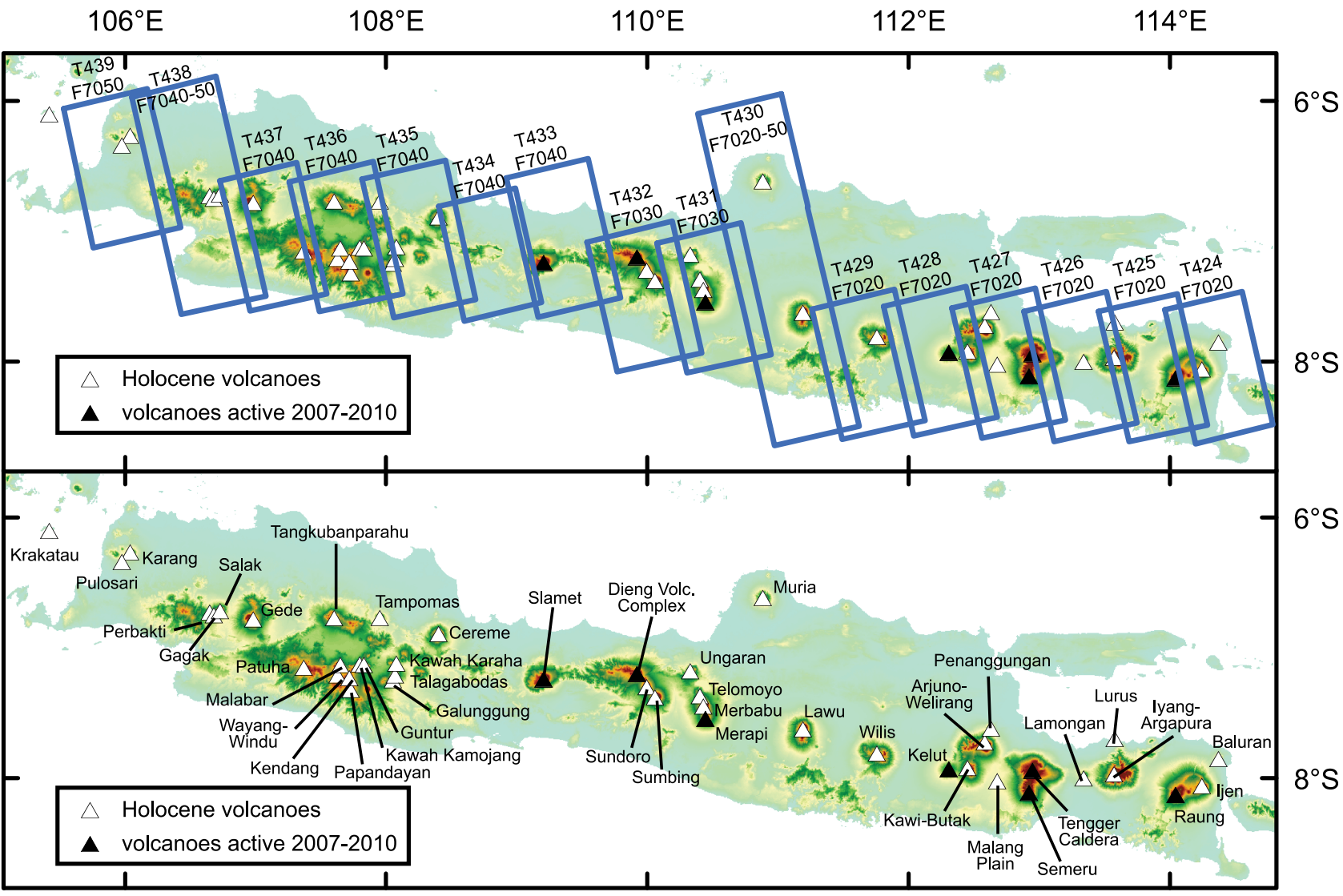

Figure 1. Topography of Java Island showing PALSAR data footprints used in this study, labeled with track (T) and frame (F) numbers. Volcanoes with Holocene activity are shown by white triangles, while those which were active during or after our study period are shown by black triangles.

until recently InSAR observations in heavily vegetated areas were limited, due to the interferometric decorrelation of C-band radar induced by rapidly changing ground vegetation. L-band radar is more effective for observation in heavily vegetated areas [Rosen et al., 1996], such as tropical volcanic arcs. The Phased Array type L-band Synthetic Aperture Radar (PALSAR) instrument on the Japanese Space Agency's Advanced Land Observing Satellite (ALOS) provided global coverage with longerwavelength L-band data [Rosenqvist et al., 2007].

[3] Tropical volcanic arcs such as those found in Indonesia and the Philippines have hundreds of volcanic centers, many of which have little to no ground-based monitoring due to socioeconomic and logistical barriers. Satellite-based InSAR observations permit continuous monitoring over broad areas. While remote sensing is not a substitute for field observation, it allows researchers to more easily identify active areas which can then be prioritized for ground-based monitoring. In this pilot study, we surveyed deformation in the volcanic areas on the Indonesian island of Java. Our results outline the capabilities and limitations of PALSARbased geodesy and provide a methodology for future deformation monitoring on Java and other heavily vegetated areas.

\section{Data and Methods}

\subsection{Temporal and Spatial Data Coverage}

[4] The PALSAR instrument is generally active during ascending passes of ALOS, but rarely during descending passes. Sixteen ascending tracks (also called "paths," numbered 424-439 with the dominantly used 34.3 degree look angle) cover the 43 Holocene volcanoes on Java (Figure 1). The orbit cycle of ALOS repeats every 45 days, but a given area may not be imaged by the PALSAR instrument during every orbit cycle. For this repeat interval, over a 2-year period a given area will be imaged a maximum of 16 times. During the years 2007 and 


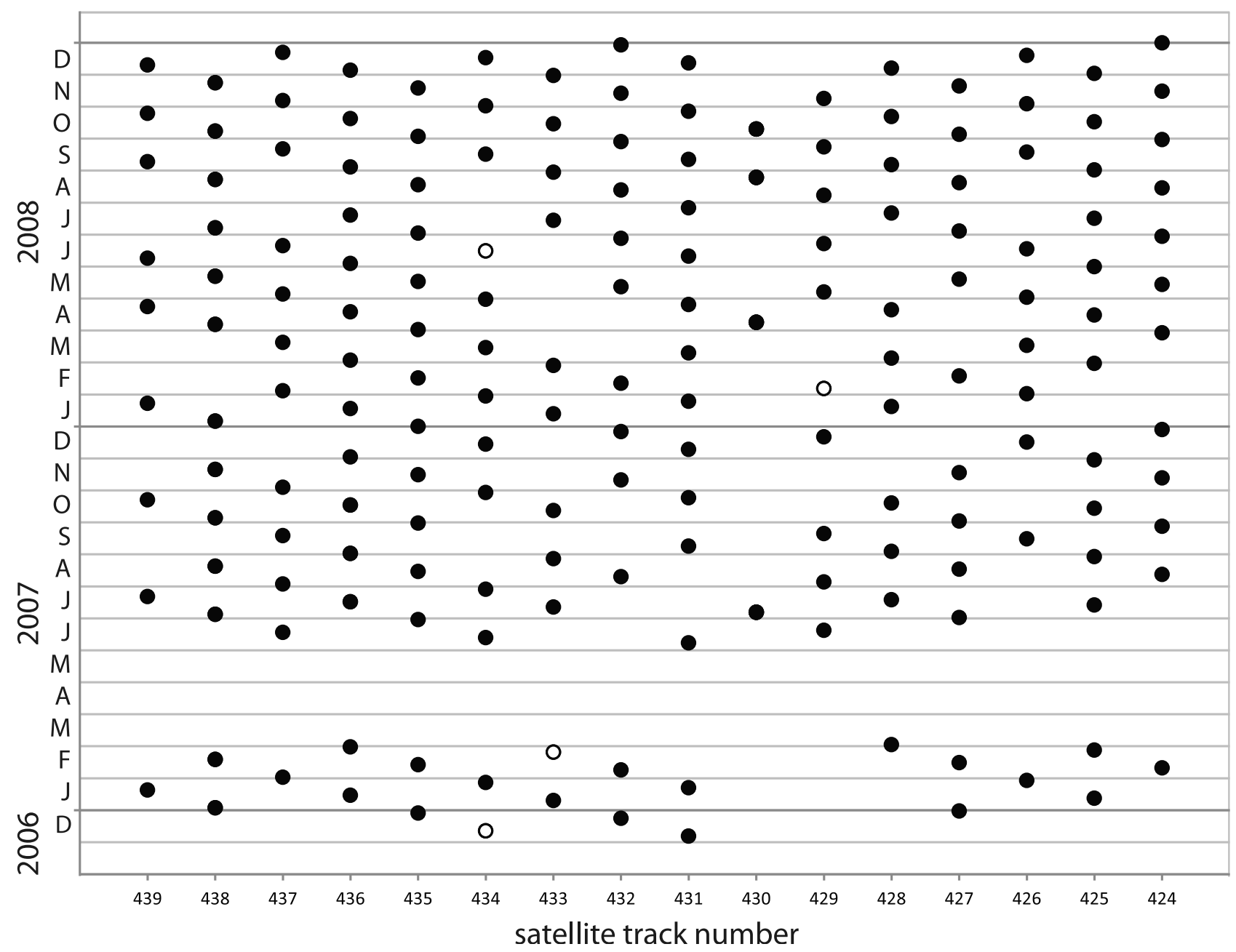

Figure 2. Dates of ascending PALSAR acquisitions in the 34.3 degree beam mode for tracks covering Java during the study period. Acquisitions shown with empty symbols could not be used in this study due to instrumental or environmental problems.

2008, each track covering Java was imaged between 9 and 14 times, with the exception of track 430 which was imaged only 4 times (Figure 2). (Due to changes in data distribution policies, PALSAR imagery from 2009 and later is less readily available.) A few of these images could not be used for our study due to unfavorable satellite position or problems acquiring the data, but the majority of the images on a given track are compatible with each other for interferometry. We used the Repeat Orbit Interferometry Package (ROI_PAC) [Rosen et al., 2004] to produce the interferograms used in this study. All interferograms for a given satellite track were produced using a common set of radar coordinates (from one radar scene chosen as the "master" in each track), which greatly facilitated the subsequent numerical analysis. This common reference frame processing method was developed by DiCaprio [2010].

\subsection{Decorrelation, Pair Selection, and Time Series Approach}

[5] The InSAR technique measures the phase change between two image acquisitions in the reflected radar signal for each pixel, which represents motion of the ground relative to the satellite. If nearby pixels all have similar phase changes, this can be interpreted as a coherent motion of an area of ground. Decorrelation occurs when the phase scattering character of the ground differs significantly between two image acquisitions. Geometric decorrelation occurs when the perpendicular component of the baseline, Bperp (the distance between the two satellite positions, measured perpendicular to the line of sight) is too large, in which case the radar beam reflects off a different set of ground scatterers. Temporal decorrelation occurs when the character and/or distribution of the ground scatterers changes 


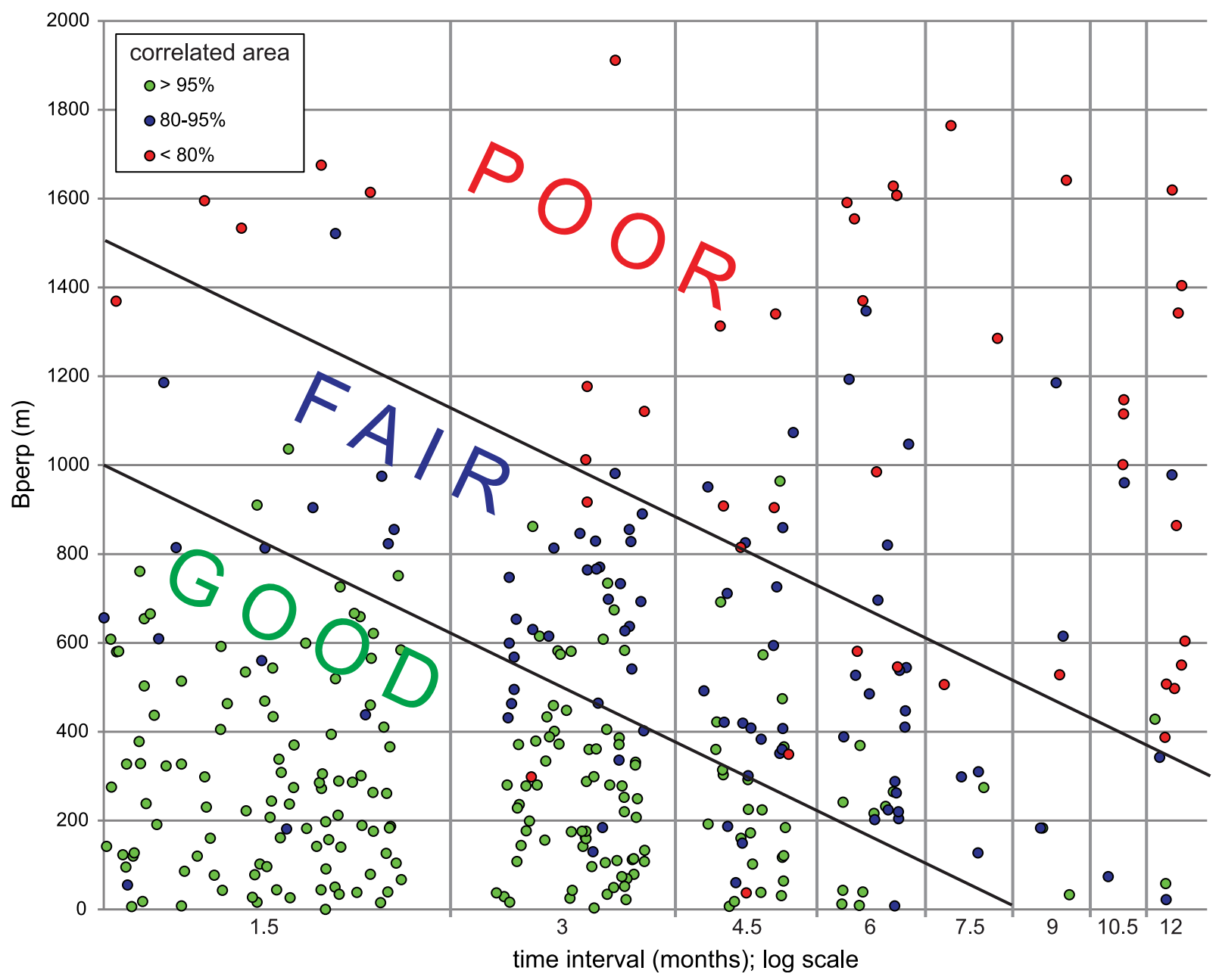

Figure 3. Degree of interferogram correlation as a function of perpendicular component of the baseline (Bperp) and time interval, showing all interferograms produced for this study. Data for each time interval have been horizontally jittered to show the complete distribution, and the time axis is logarithmically scaled. Correlation generally decreases with longer baselines and time intervals, so the plot can be divided into three fields in which the majority of the interferograms have either good, fair, or poor correlation. Interferograms spanning time intervals longer than 6 months rarely have good correlation, and even at the shortest available time interval (45 days), interferograms with Bperp longer than $800 \mathrm{~m}$ rarely have good correlation. Because volcanic edifices are among the areas most likely to be decorrelated, a high percentage of correlated area $(>95 \%)$ is typically required for successful survey of volcanic deformation.

between the two images, which can happen quite rapidly in vegetated areas due to motion, growth, or destruction of plant matter [Zebker and Villasenor, 1992]. Since decorrelated areas cannot be interpreted in terms of ground deformation, we choose image pairs such that decorrelated areas are minimized. This choice is particularly important for our study since areas of high topographic relief, such as volcanic edifices, are more likely to be decorrelated.

[6] When the objective is to detect potentially slow deformation, the most efficient strategy may be to make interferograms spanning long time periods so that the magnitude of the deformation is as high as possible. However, this approach fails for Java due to temporal interferogram decorrelation. While the 23.6-cm-wavelength L-band radar used by PALSAR is not as effectively scattered by rapidly changing small leaves and twigs as 5-cmwavelength $\mathrm{C}$-band radar, it is still scattered by larger leaves and branches. Interferograms spanning time intervals of 6 months or longer usually have large decorrelated areas (Figure 3). Longer Bperp also generally increases the percentage of decorrelated area, but at the shortest time intervals, Bperp values up to $800 \mathrm{~m}$ usually produce good 


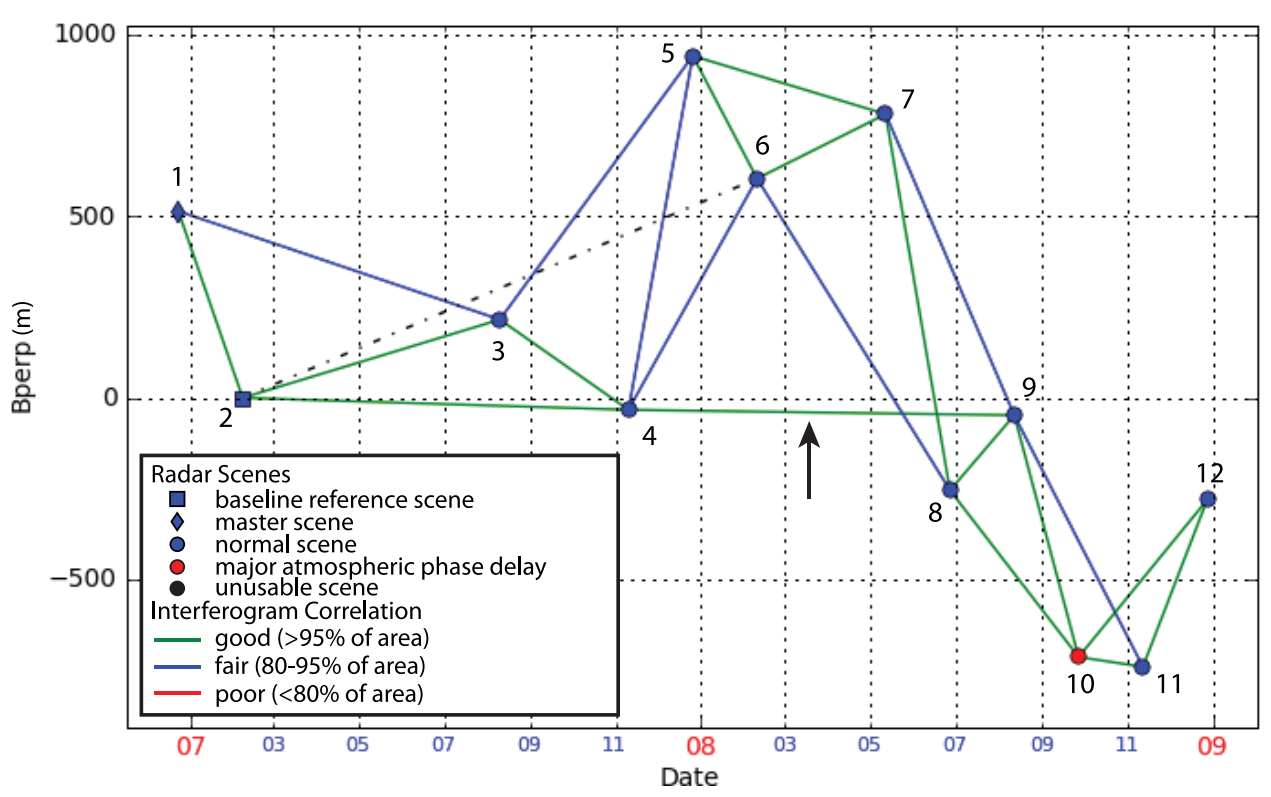

Figure 4. Bperp versus time plot showing the set of interferograms used for track 432 as an illustration of the scene pair selection approach used for all tracks. Radar scenes are numbered sequentially in time. All interferograms spanning one or two time intervals between radar acquisitions are included. In this strategy it is generally preferable to include scenes dominated by atmospheric phase delay such as scene 10 , as excluding any scene results in longer time intervals and consequent larger decorrelated areas. Such scenes are better excluded only if they are at the beginning or end of the time series, and would thus dominate the resultant sums. The arrow indicates a short-Bperp interferogram spanning five time intervals that was included because it spans two time intervals (between scenes 4-5 and 7-8) that were otherwise covered only by long-Bperp pairs. Red numbers on the date axis are YY calendar years and blue numbers are MM months. Black dashed line is the 1-year interferogram shown for comparison in Figure 6 (which was not included in the analysis).

results. Therefore, the best strategy is to make interferograms from pairs with the shortest available time intervals, in a continuous series so that all time periods are covered. This approach also has an advantage over more traditional "stacking" in that we obtain a time series of deformation, rather than just a total or an average rate of deformation.

[7] For a given satellite track, we produced an interferogram of each pair of sequential radar image acquisitions, and of each pair of images that have one intervening acquisition. In this manner, each time interval between sequential acquisitions (except the first and final intervals) is covered by three interferograms. We also add interferograms covering more than two time intervals which have very short baselines (Figure 4). Thus, our set of interferograms covers every time interval, using all of the pairs which are likely to have small percentages of decorrelated area. When a particular area is decorrelated during a time interval in all of our selected interferograms that cover that time interval, it is unlikely that it would be correlated in any other interferogram covering that interval (since seasonal changes are minimal in the equatorial region).
[8] InSAR phase change values are not absolute measurements; apparent motion in one part of an interferogram can be interpreted only relative to other parts of the image. In the context of searching for deformation signals associated with isolated magmatic centers, it is safe to proceed assuming that most of the region covered by the interferometric image is not deforming. While there may be long wavelength deformation caused by large scale tectonic processes such as subduction, these processes are effectively noise for the present study. A spatial ramp for each interferogram is fitted and removed as part of the baseline re-estimation process within ROI_PAC. To produce the deformation time series, we first subtract from each unwrapped interferogram its median phase change value, since we assume that most of the area in the image is not moving relative to the satellite. Then, we perform a least squares inversion for the phase change at each pixel during each time interval. For a series of radar acquisitions at sequential times $A, B, C, D \ldots$ we solve the following matrix equation for the unknowns $\varphi_{i j}$, each of which is the phase changes at a given pixel between times $i$ and $j$, using the phase changes at that pixel in 
each interferogram $I_{i j}$ covering the interval between times $i$ and $j$ :

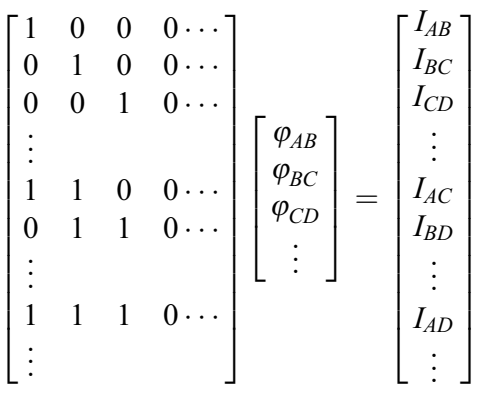

$$
\begin{aligned}
& \mathbf{G} \boldsymbol{\Phi}=\mathbf{I}
\end{aligned}
$$

The first group of rows represent the set of singletime-interval interferograms, the second group is the two-time-interval set, and the third comprises any additional multiple-time-interval interferograms that are included to improve correlation over longBperp pairs. This matrix equation approach is very similar to the Small Baseline Subset (SBAS) algorithm [Berardino et al., 2002], but because our interferogram sets are completely interconnected, the resultant matrix is over-determined. Therefore, there is no need to resort to the singular value decomposition and minimization procedures often used in SBAS. If a pixel is decorrelated in only one interferogram, the $\mathbf{G}$ matrix is still full rank and a solution can be determined. In the event that a pixel is decorrelated in several short-interval interferograms but correlated in a longer-interval interferogram that includes the shorter intervals (e.g., all rows missing from the matrix equation except the $I_{A D}$ row), the data are temporally interpolated assuming a linear rate of deformation, e.g., assuming:

$$
\frac{\varphi_{A B}}{t_{A B}}=\frac{\varphi_{B C}}{t_{B C}}=\frac{\varphi_{C D}}{t_{C D}}
$$

where $t_{i j}$ is the amount of time elapsed between times $i$ and $j$. Such rare situations are our only application of interpolation. The resultant time step images (Figure 5) have "holes" in the data only in areas which are decorrelated in every interferogram covering that time period (i.e., the $\mathbf{G}$ matrix was singular even after the addition of equation (2)). Finally, we convert the phase change (in radians) to line-ofsight (LOS) displacement (in centimeters), and produce summed stacks which represent total deformation over the entire observation period. Any data "hole" which appears in any of the time intervals will also appear as a hole in the summed stack, since the sum cannot be computed. Despite this, the percentage of decorrelated area in a summed stack is usually much lower than in a single interferogram covering the same time period (Figure 6), illustrating the value of choosing interferograms covering short time intervals.

\subsection{Tropostatic Correction}

[9] Propagation path delays which produce noise in InSAR deformation data are primarily due to atmospheric processes: temperature, pressure, and humidity variations in the troposphere can produce phase delays equivalent to decimeters of deformation, and changes in ionosphere conditions can produce even greater delays. Atmospheric conditions are generally uncorrelated between satellite image acquisitions, so atmospheric noise can be identified as signal that is associated with one particular image acquisition and cancels out in summed "stacks" of interferograms. However, when tropospheric properties vary with altitude (which frequently occurs), the atmospheric signal produced correlates with topography and can thus mimic deformation of a volcanic edifice (Figure 7). To minimize such signals, we used a multiscale method [Lin et al., 2010] to estimate and remove tropostatic phase delay from all interferograms. For each interferogram, this method estimates the linear correlation of LOS displacement with elevation as the value $\mathrm{K}$ (expressed in centimeters of LOS displacement per kilometer of elevation), and computes the best fit K-value for each radar scene (such that an interferogram $\mathrm{K}$-value is the difference between its master and slave radar scene K-values). Interferogram $\mathrm{K}$-values for the time intervals in our data set have magnitudes up to $3 \mathrm{~cm} / \mathrm{km}$ (Figure 8 ). These best fit linear tropostatic signals are then subtracted from each interferogram (Figure 7), a conservative correction which has the effect of removing much of the high-magnitude random variability from our interferogram time series (Figure 9), but may not remove higher-order tropostatic effects. Since $\mathrm{K}$-values are fit over the entire interferogram, we can be reasonably confident that this correction will not remove volcanic deformation (which might be coincidentally correlated with elevation, but would be limited to a small part of the image.) We make no attempt to remove turbulent tropospheric or ionospheric phase delay.

\section{Results}

[10] Our survey highlights a number of deformation events across Java during 2007-2008. The most 


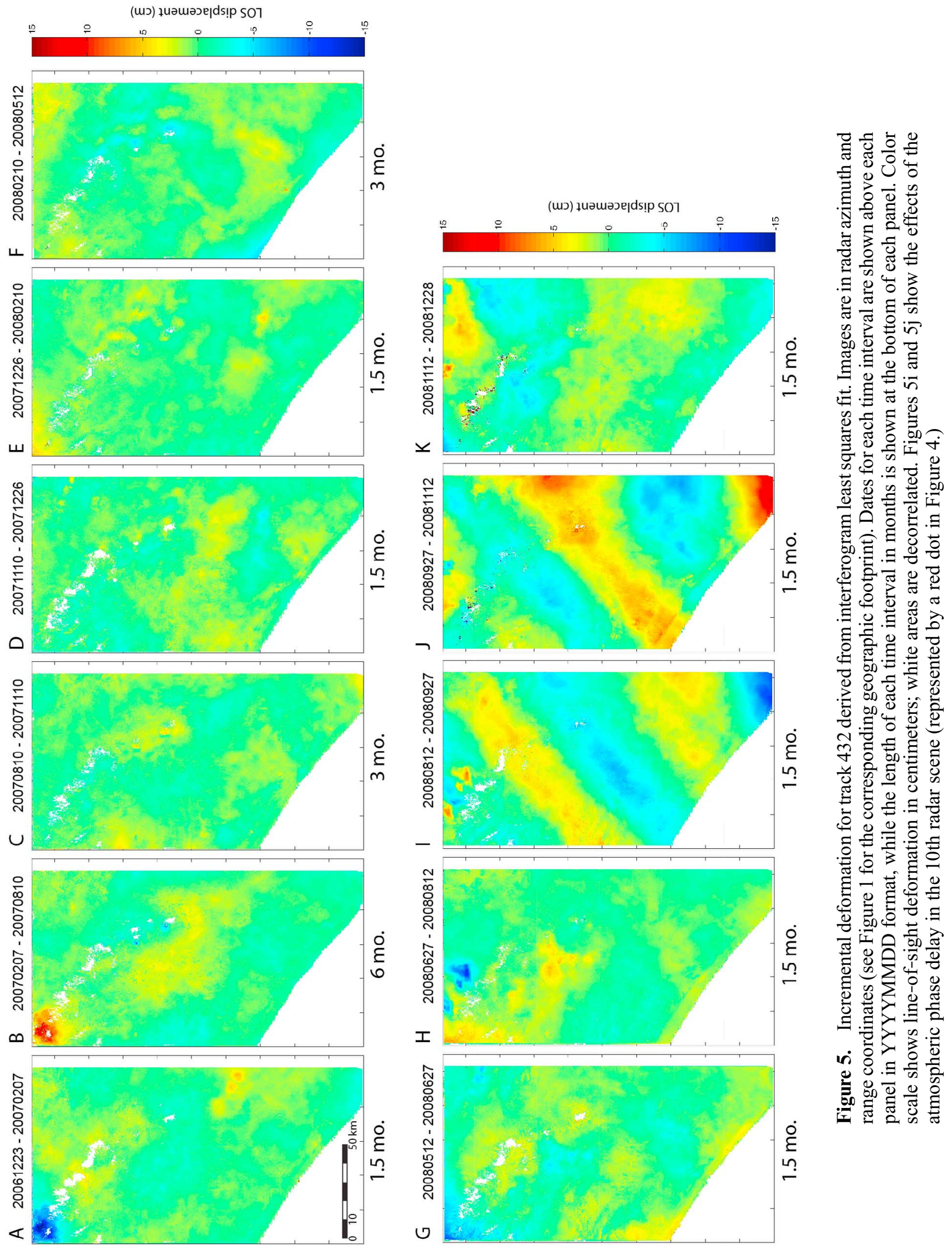



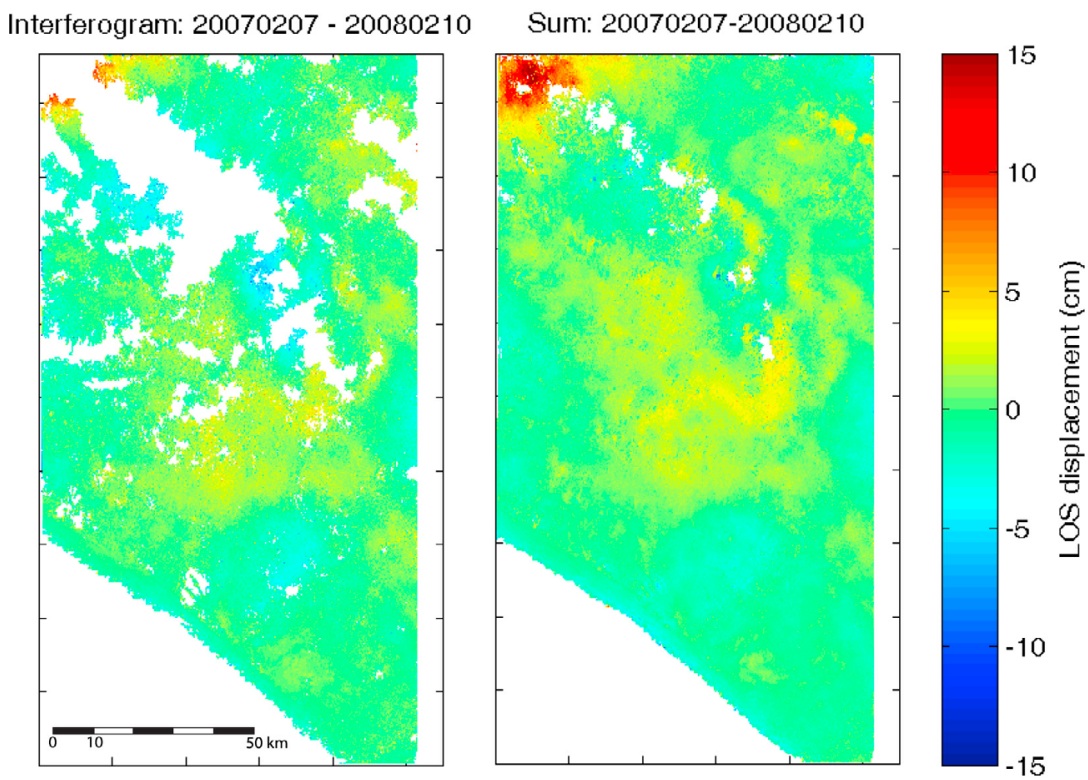

Figure 6. Comparison of a 1-year interferogram (dates are in YYYYMMDD format) with the corresponding sum of shorter time steps for track 432. Images are in radar azimuth and range coordinates (see Figure 1 for the corresponding geographic footprint). The same signal pattern can be discerned in both images (with minor amplitude differences due to the tropostatic and median value corrections applied during the time series analysis), but the single interferogram has a much larger decorrelated area than the time series sum.

notable results are presented below, while the complete time series for all tracks appear in the auxiliary material. ${ }^{1}$

\subsection{Detection Limits Imposed by Atmospheric Noise}

[11] As we noted above, the tropostatic correction is quite conservative and does not remove all the atmospheric signal. Our time step images contain tropospheric signals with magnitudes commonly as great as $5 \mathrm{~cm}$, and less frequently as great as $10 \mathrm{~cm}$ (see Figures $5 \mathrm{i}$ and $5 \mathrm{j}$ for an example). Ionospheric conditions occasionally produce signals up to $15 \mathrm{~cm}$. We can easily distinguish semi-permanent deformation from atmospheric noise by producing two independent sums, one spanning the first through penultimate time periods and one spanning the second through last time periods (Figures 10a and 10b). Any signal which does not appear in both sums is associated with the first or last time periods only, and is therefore probably atmospheric signal associated with one particular image acquisition. In general, a signal trend which continues over several time periods is likely to be real ground deformation. Once the real deformation signals are identified, the

\footnotetext{
${ }^{1}$ Auxiliary materials are available in the HTML. doi:10.1029/ 2011GC003775.
}

total net deformation can be seen by summing over all the time periods (Figure 10c), and temporal variation can be studied by producing a time series plot for a given point. However, due to the nature of atmospheric noise we cannot detect variation in deformation on time scales less than or equal to the time intervals between acquisitions, and/or with magnitudes less than $\sim 5 \mathrm{~cm}$. For example, a lowmagnitude volcanic inflation/deflation monthly cycle would be indistinguishable from atmospheric noise. Consequently, there is $\sim 5 \mathrm{~cm}$ of uncertainty in our deformation measurements, which dwarfs the millimeter-scale instrumental and processing uncertainties.

\subsection{Likely Volcanic Deformation}

[12] To detect volcanic deformation, we examined independent sums for each track to identify sources of permanent deformation which are associated with volcanic centers. In addition, to highlight more temporary trends which may not be obvious in sums over longer time periods, we also produced a deformation time series for a point on the peak of each volcanic edifice which has experienced Holocene activity. The majority of these time series were indistinguishable from atmospheric noise, indicating that there was no deformation within our detection limits. Those which did exhibit detectable 

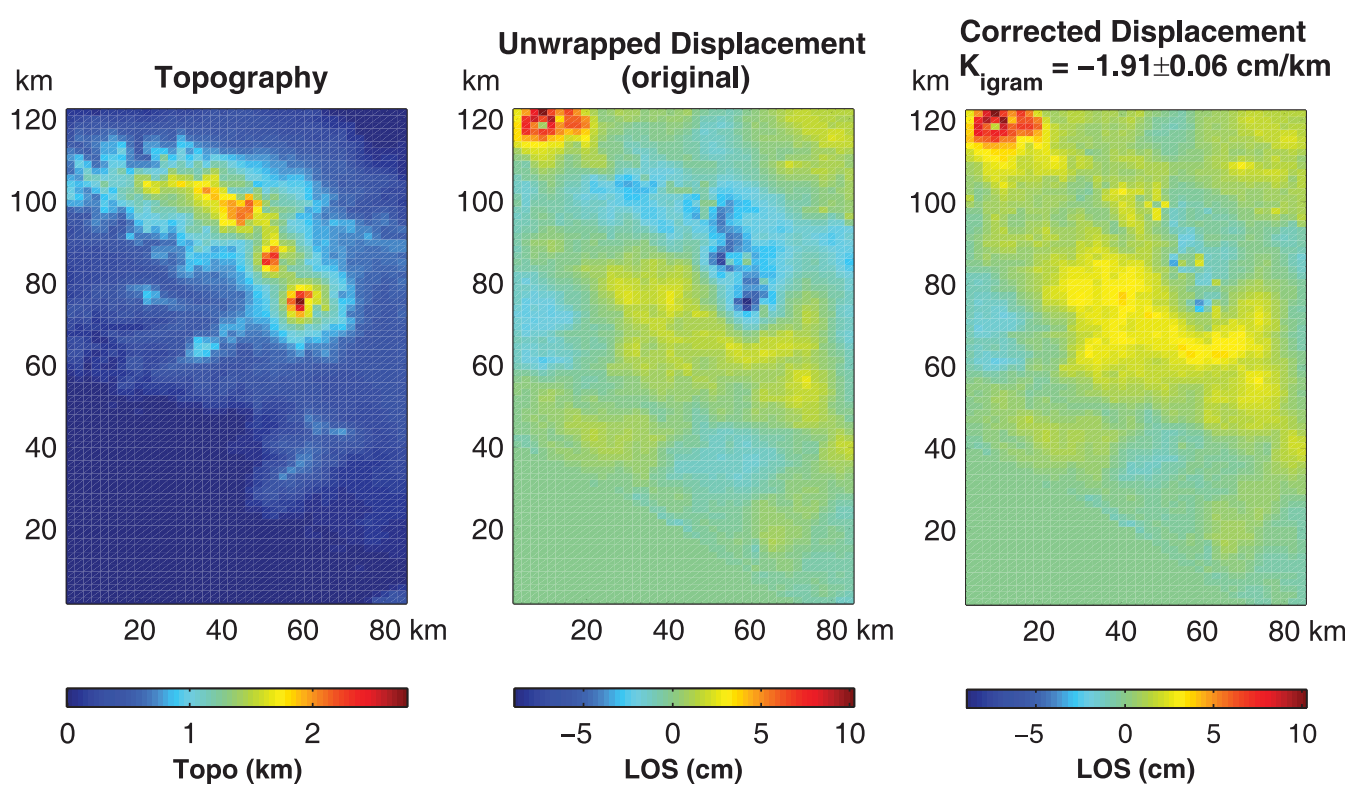

Figure 7. Example of the tropostatic correction (here applied to the interferogram covering $7 \mathrm{Feb}$ to $10 \mathrm{Aug} 2007$, the second time interval in the track 432 time series). The original interferogram (center) had a strong negative signal associated with high topography (left). The correlation between LOS displacement and elevation was estimated to be $-1.91 \mathrm{~cm} / \mathrm{km}$, and this scaling factor was subtracted from the interferogram (right). Small negative signals associated with the two highest topographic points remain after the correction; these may be due to very local tropospheric effects. The strong positive signal in the upper left corner of the interferogram is also atmospheric in origin, but since it is not correlated with topography it is unaffected by this correction.

deformation are discussed below; the remainder can be found in the auxiliary material.

\subsubsection{Lamongan}

[13] One of the most prominent areas of net deformation during the study period of 2007-2008 is associated with the volcano Lamongan in east Java. A roughly circular area centered northwest of the edifice moved toward the satellite between 15 September and 16 December 2007 with a central LOS change of $\sim 12 \mathrm{~cm}$, consistent with volcanic inflation (Figure 11a.) Eight subsequent image acquisitions make it clear that the area was essentially stable following the deformation event, but only two prior acquisitions (separated by 7.5 months) leave the behavior before the deformation event poorly constrained (Figure 11c). The deformation occurred during a 3-month time period, but could have been much shorter in duration.

[14] Having measured only one component of the deformation, it is not very fruitful to attempt to invert the deformation data to model the inflation source. Even when deformation has been imaged from multiple viewing geometries, there are generally a wide range of models which can fit the data equally well [Pritchard and Simons, 2004b]. However, it is instructive to attempt to reproduce the deformation with forward models. Modeling a magma chamber with a basic spherically symmetric point-source pressure change in an elastic half-space [Mogi, 1958], we calculate a synthetic interferogram which approximately reproduces the observed signal (Figure 12a). Our preferred model (model 1), with a volume increase of $9.2 \times 10^{6} \mathrm{~m}^{3}$ at $4 \mathrm{~km}$ depth, matches the north-south profile of the data very well, but fails to capture the shape of the west-

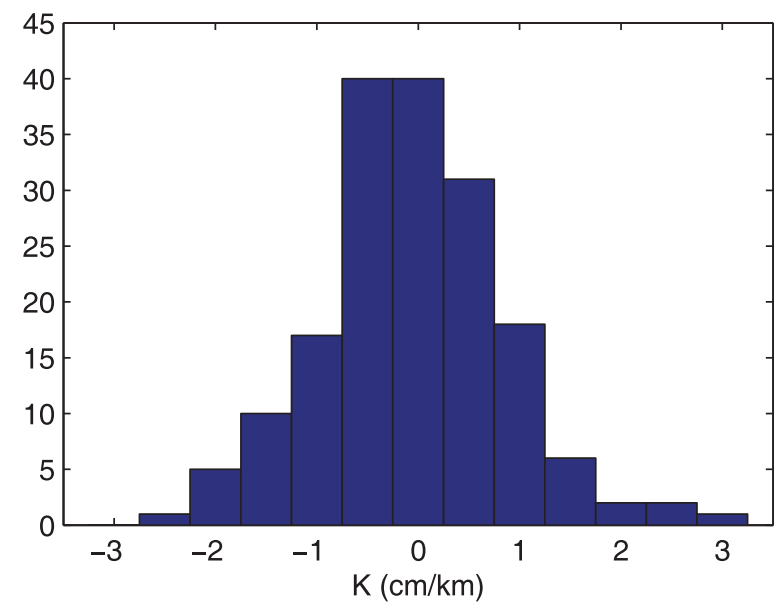

Figure 8. Histogram of tropostatic correction factor $\mathrm{K}$-values for the 173 time intervals in this study. 

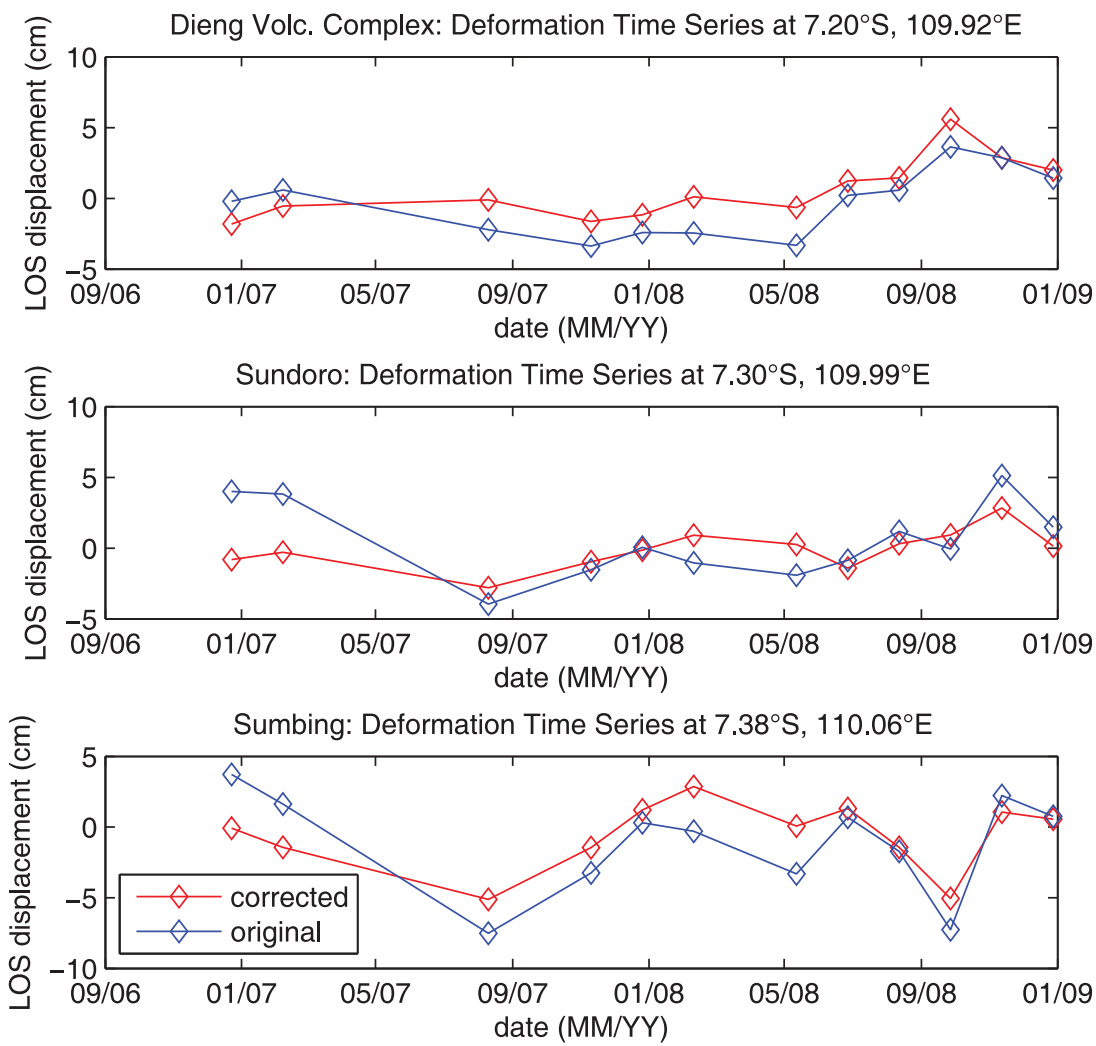

Figure 9. Comparison of volcanic edifice point time series with and without the tropostatic correction. Displacements are shown relative to the median value for each time series. The tropostatic correction reduces the magnitude of shortterm fluctuations (most apparent in the first two time intervals). The Dieng Volcanic Complex, Sundoro, and Sumbing are the three Holocene volcanoes covered by track 432 (locations shown on Figure 10). The Dieng Complex exhibits a positive (inflation) trend of about $4 \mathrm{~cm}$ starting at the beginning of 2008 which may reflect real deformation; the time series of the other two volcanoes are indistinguishable from atmospheric noise.

east profile (Figure 12b). For an east-looking satellite observing deformation caused by a spherical Mogi source, the signal should have a steep west flank and a tapering east flank, whereas the observed signal has the opposite asymmetry. Different depths and sizes of magma volume increase can match the east or west flank of the $\mathrm{W}-\mathrm{E}$ profile (Figure 12b, models 2 and 3 ), but these models poorly match the $\mathrm{N}-\mathrm{S}$ profile and there is no way to match the complete W-E profile with a spherical Mogi source. Therefore, we consider model 1 to be the best fit to the data out of this set of simple models (parameters for all models are shown in Table 1).

[15] The unexplained asymmetry in the $\mathrm{W}-\mathrm{E}$ profile may be due to atmospheric contamination of the volcanic inflation signal, to a slight asymmetry in the magma body, or to heterogeneity in the sub-surface. To attempt to distinguish which is the case, we also produced forward models to fit the sum of all the time steps (Figure 12c). The sum contains atmospheric signal only from the first and last image acquisitions (28 January 2007 and 18 December 2008), which is independent of any atmospheric signal in the Sep-Dec 2007 time step. In this case, the north-south profile is again well-matched by a Mogi source similar to model 1 (Figure 12d, model 4), and there is still unexplained asymmetry in the west-east profile, though it is not as prominent. Again, models can be made to more accurately reproduce the east or west flank of the deformation signal (models 5 and 6), but cannot fit both flanks. Since the independent time step and sum both have an east-west asymmetry which cannot be fit with a spherical Mogi source, we conclude that the asymmetry of the signal is being produced by an asymmetry in the magma body or sub-surface heterogeneity.

[16] Though we cannot tightly constrain the details with the data available, this signal very likely represents an intrusion of magma at a depth of a few kilometers. The Lamongan edifice itself was frequently active throughout the 19th century, 


\section{A}

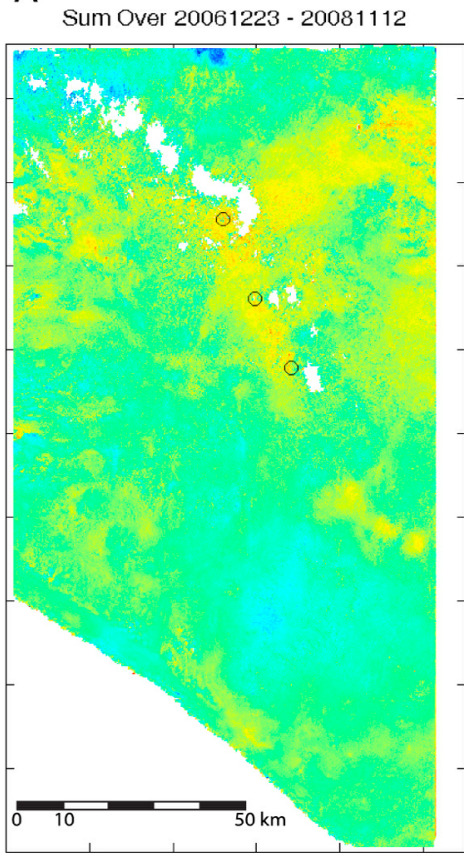

B Sum Over 20070207 - 20081228

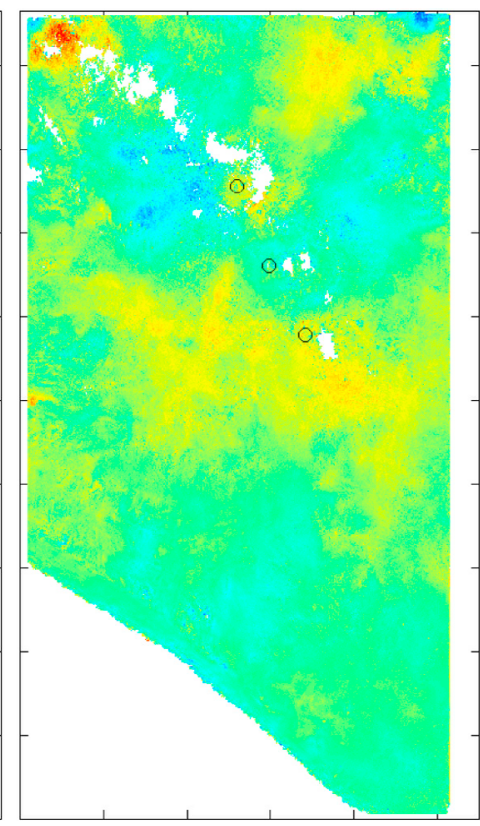

C Sum Over 20061223 - 20081228

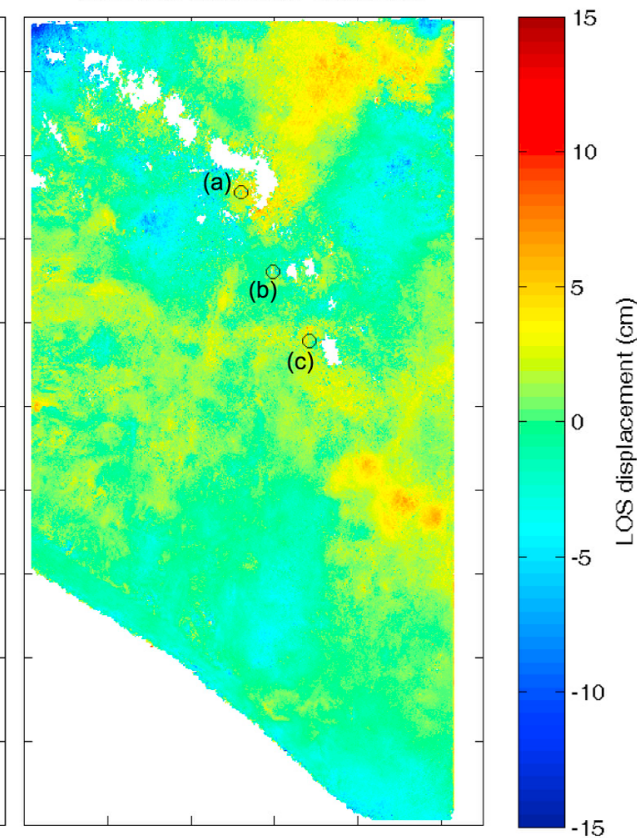

Figure 10. Example of independent sum method for distinguishing semi-permanent deformation from atmospheric noise, applied to track 432. Dates are in YYYYMMDD format. Black circles show locations of volcanoes with point time series shown in Figure 9: (a) Dieng Complex, (b) Sundoro, (c) Sumbing. Signal patterns which appear in both independent sums (Figures 10a and 10b) can be interpreted as real deformation, and the full extent of this deformation over the entire study period can be seen in Figure 10c. The Dieng Complex exhibits a fairly robust positive (inflation) trend of about $4 \mathrm{~cm}$ (see Figure 9), and there is a low-amplitude pattern throughout the southern part of the image that is probably related to hydrology.

producing lava flows and Strombolian eruptions every few years, and is surrounded by scattered prehistoric volcanic maar craters and cinder cones. The volume change we estimate is similar to calculated juvenile magma volumes for maar eruptions in this volcanic field, as well as to typical 19thcentury summit eruptions [Carn, 2000]. We cannot determine whether this newly filled magma body will crystallize in place or eventually erupt, but if it does erupt it could easily form another volcanic maar or produce a summit eruption.

[17] It is also interesting to note that an upper crustal volcanic seismicity swarm occurred in the same area northwest of the Lamongan edifice on 4-6 January 2005 [Center for Volcanology and Geological Hazard Mitigation (CVGHM), 2005], 2.5 years prior to the deformation event we detected. This swarm may not have been directly related to the 2007 deformation event, but likely resulted from an earlier magmatic intrusion in the same area. Several previous swarms that occurred during the 20th century were all located west of the Lamongan edifice [Smithsonian Institution, 1985, 1988], so the deformation we observe is consistent with the locus of activity suggested by seismicity. Due to these repeated seismic swarms, local scientists have identified Lamongan as a monitoring priority [CVGHM, 2005], and our deformation observation reinforces the importance of continued monitoring.

\subsubsection{Slamet}

[18] The signal associated with the volcano Slamet in central Java is far less prominent in magnitude and spatial extent than the Lamongan signal (Figure 13a), but is revealed as a notable trend in the edifice time series (Figure 13b). The small $(\sim 5 \mathrm{~cm})$ magnitude of the signal makes it more difficult to determine the timing of this inflation event, but the time series is consistent with a steady rate of LOS change of $\sim 3 \mathrm{~cm} / \mathrm{yr}$. This signal in the sum over all time steps (12 July 2007 to 29 November 2008) can be approximately reproduced by a $5 \times 10^{5} \mathrm{~m}^{3}$ volume increase at $1.5 \mathrm{~km}$ depth (Figure 13c), though the considerable noise and moderate atmospheric contamination in the data make the quality of the fit 

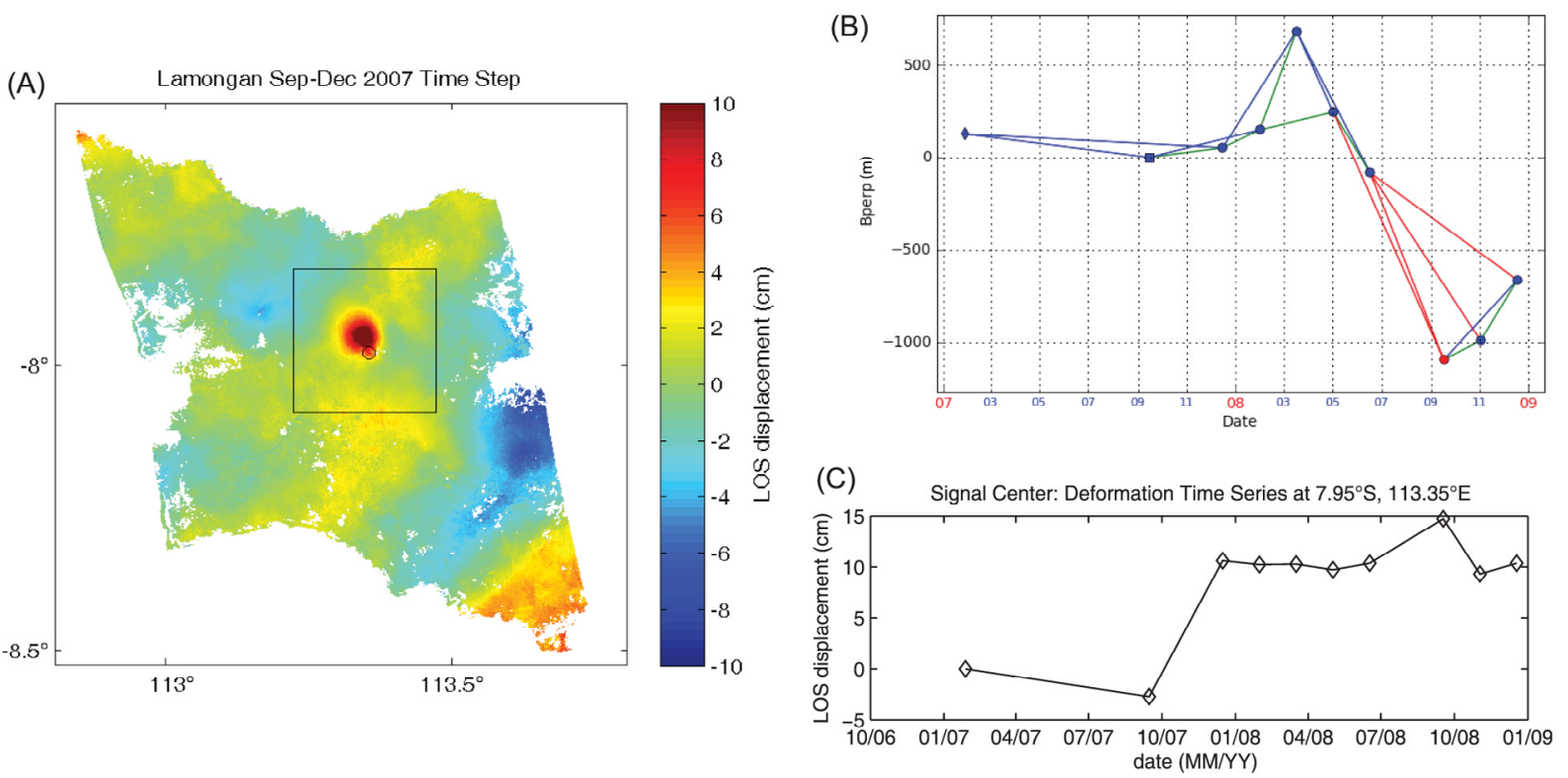

Figure 11. Lamongan volcano deformation. (a) Georeferenced second time step from track 426, spanning 15 Sep to 16 Dec 2007. Black circle shows the location of the Lamongan edifice; box shows area of panels in Figure 12a and 12c. (b) Bperp versus time plot showing interferograms used for this track; symbology as in Figure 4. (c) Time series at the center of the deformation signal. Note that the temporary deviation from the flat post-deformation trend corresponds to a scene dominated by atmospheric noise, represented by a red dot in Figure 11b.

less clear. In this case the preferred model (model 1) is a better fit to the $\mathrm{W}-\mathrm{E}$ profile than the $\mathrm{N}-\mathrm{S}$ profile (Figure 13d). A volume increase of $3 \times 10^{5} \mathrm{~m}^{3}$ at $0.8 \mathrm{~km}$ depth (model 2) is a somewhat better match to the $\mathrm{N}-\mathrm{S}$ profile, but poorly reproduces the $\mathrm{W}-\mathrm{E}$ profile. This volcano later erupted in April-June of 2009 [Smithsonian Institution, 2009a, 2010], so this relatively shallow magma body may have erupted a few months after our study period ended. Slamet is one of Java's most active volcanoes, experiencing significant eruptions every few years since the beginning of consistent record-keeping in the early 1800s [Neumann van Padang, 1951a; Smithsonian Institution, Slamet: Eruptive history, Global Volcanism Program, 2010, http://www.volcano. si.edu/world/volcano.cfm?vnum=0603-18=\&volpage= erupt]. Extending InSAR study to the time of the 2009 eruption and beyond could potentially illuminate the spatiotemporal relationships between ground deformation and eruption; we were unable to do this due to limitations in accessing PALSAR data for that time period.

\subsubsection{Others}

[19] There are three other volcanoes which exhibit signals above our stated detection threshold of $5 \mathrm{~cm}$ : Perbakti-Gagak, Gede, and Kelut. However, while these appear to be real deformation, they may not be magmatic in origin. There is a fairly widespread, locally heterogeneous subsidence signal associated with Perbakti-Gagak in west Java (Figure 14), which is probably related to hydrothermal activity and fluid extraction for geothermal power generation. This volcanic area has vigorous hydrothermal activity and was the site of numerous phreatic eruptions in the $1920 \mathrm{~s}$ and $30 \mathrm{~s}$ [Neumann van Padang, 1951b], so this style of deformation is not unexpected.

[20] There is a significant deformation signal associated with the volcano Gede, located southeast of Jakarta in west Java (Figure 15). An area on the east flank of the edifice receded $\sim 7 \mathrm{~cm}$ from the satellite between 18 Sep 2007 and 21 Dec 2008, following a time series trend consistent with a steady rate of LOS change of $\sim 5 \mathrm{~cm} / \mathrm{yr}$. The time series at the peak of the Gede edifice shows no such trend and is indistinguishable from pure atmospheric noise. While the flank deformation may reflect a volcanic process, it is very similar in character and magnitude to the hydrologic deformation which occurs commonly throughout Java (see section 3.3 below), and is notable only because of its proximity to a volcanic edifice. The most likely cause of this deformation is groundwater extraction. However, Gede was 
(A)
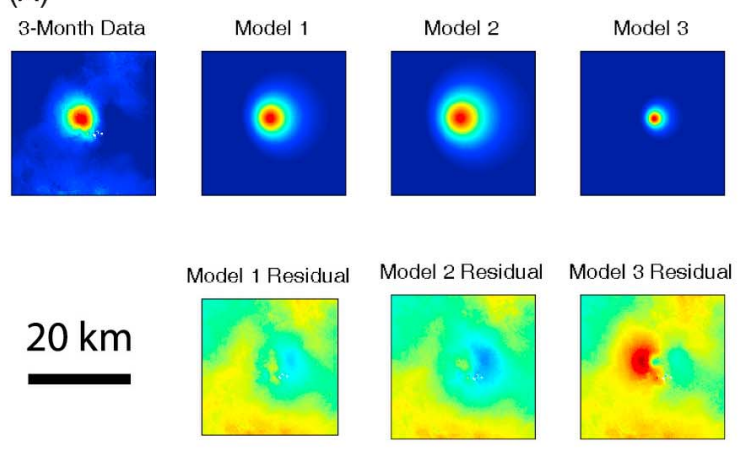

(C)
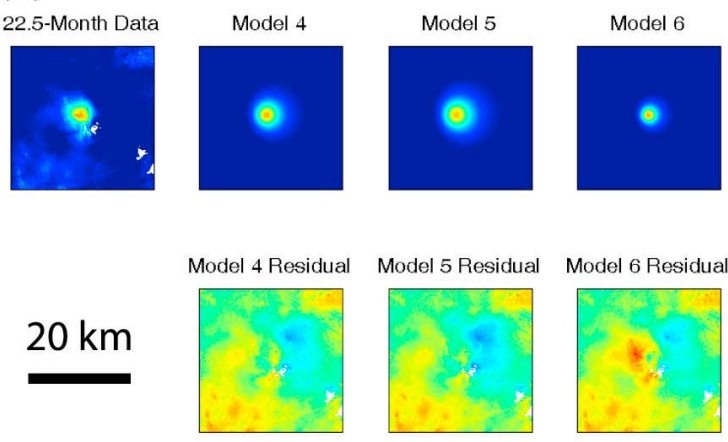

(B)
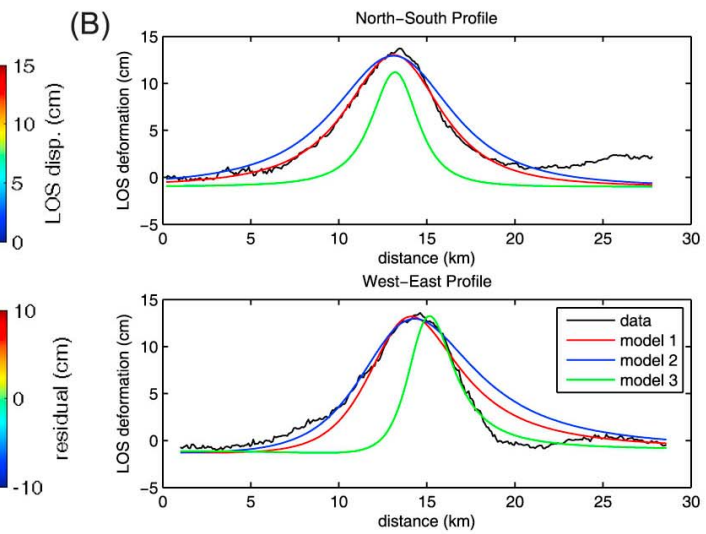

(D)
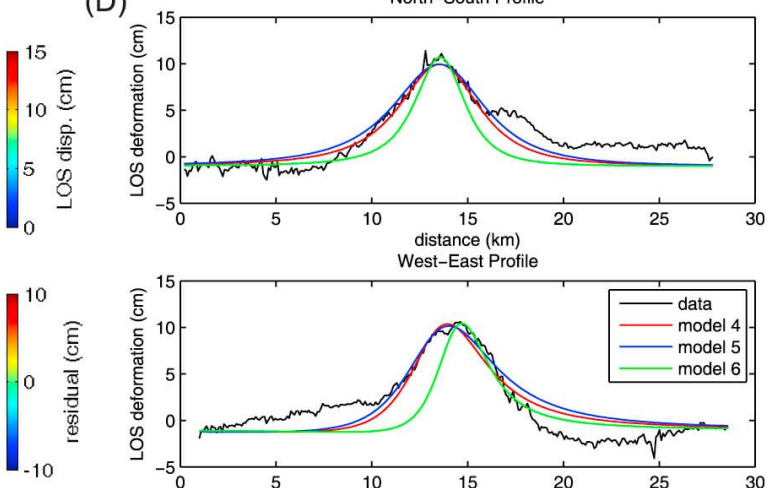

Figure 12. Modeling of Lamongan deformation. (a) Data, source model synthetic interferograms, and residuals for the 3-month time step. (b) N-S and W-E profiles of 3-month data and models. (c) Data, source model synthetic interferograms, and residuals for the 22.5-month sum spanning 28 Jan 2007 to 18 Dec 2008. (d) N-S and W-E profiles of 22.5month data and models.

frequently active throughout the 19th and first half of the 20th centuries [Neumann van Padang, 1951c; Smithsonian Institution, Gede: Eruptive history, Global Volcanism Program, 2010, http://www.volcano. si.edu/world $/$ volcano.cfm?vnum $=0603-06=\&$ volpage $=$ erupt], so it is plausible that there is still magma activity beneath the edifice.

[21] The volcano Kelut in east Java (Figure 16) displays a possible 15-cm LOS change in late 2008. However, since there are only two radar acquisitions in our time series after this change, it is difficult to judge whether this was permanent, real deformation rather than a short-term atmospheric effect. The apparent deformation area is only a few hundred meters wide, limited to the very top of the Kelut edifice. This is interesting since Kelut extruded a lava dome from its crater lake from August 2007May 2008 [Smithsonian Institution, 2008a, 2008b]. The volcano did not exhibit significant deformation before or during the dome extrusion in our time series (there are some fluctuations, but with a mag- nitude of $\sim 5 \mathrm{~cm}$ we cannot confidently distinguish them from atmospheric variations). If the late-2008 inflation signal reflects real uplift, it may reflect increasing magmatic pressure within the edifice, which could instigate renewed lava dome extrusion.

[22] Numerous other volcanic edifices exhibit shorter-term positive or negative trends with magnitudes less than $5 \mathrm{~cm}$ (see Figure 9, top, for one example and the auxiliary material for others). However, the signal patterns are typically fairly diffuse with uneven edges, which is more typical of

Table 1. Magmatic Inflation Source Models for Lamongan Deformation

\begin{tabular}{ccc}
\hline Model & Depth $(\mathrm{km})$ & $\Delta \mathrm{V}\left(\mathrm{m}^{3} \times 10^{6}\right)$ \\
\hline 1 & 4 & 9.2 \\
2 & 5 & 140.0 \\
3 & 2 & 2.3 \\
4 & 3 & 4.2 \\
5 & 3.5 & 5.6 \\
6 & 2 & 1.9 \\
\hline
\end{tabular}



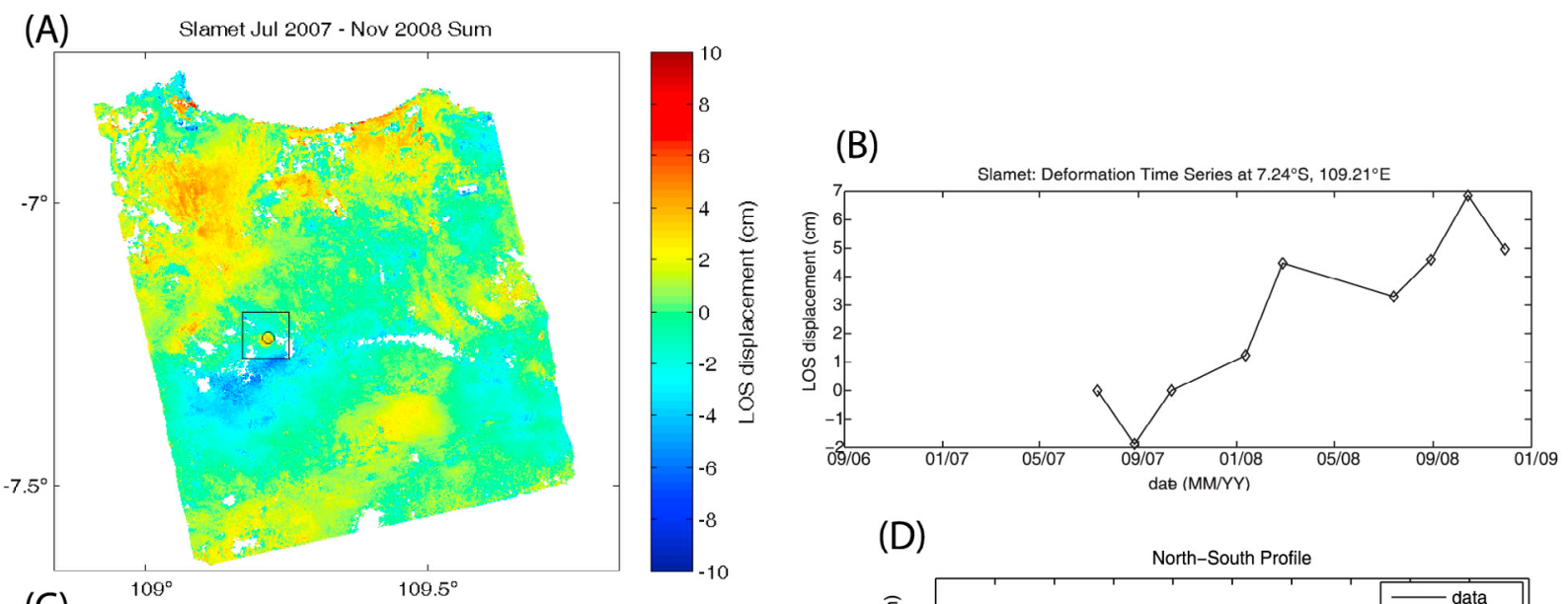

(C)
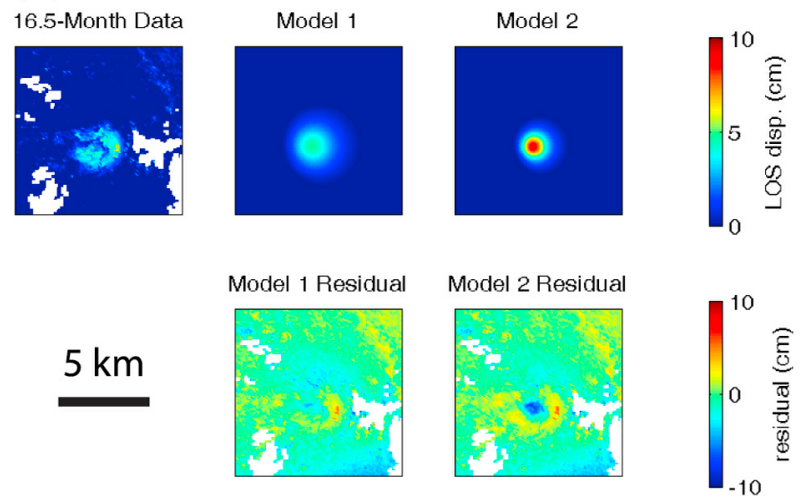
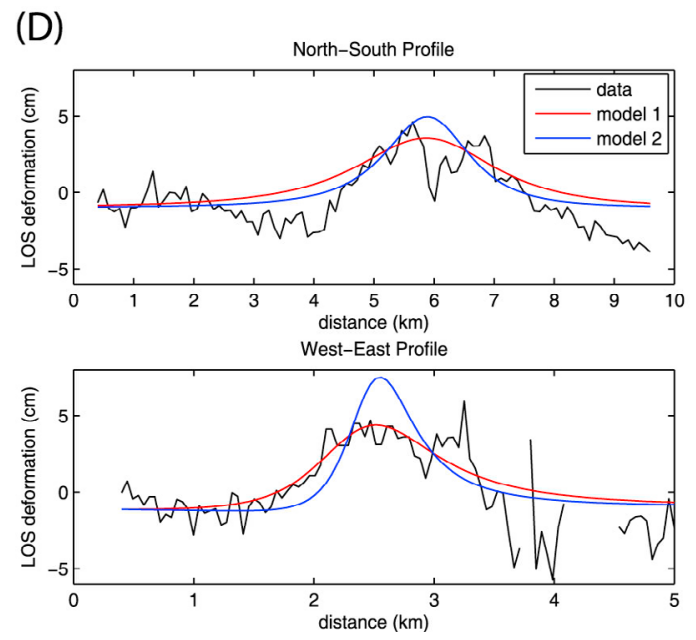

Figure 13. Analysis of Slamet volcano deformation. (a) Georeferenced sum of track 433 spanning 12 Jul 2007 to 29 Nov 2008. Black circle shows the location of the Slamet edifice; box outlines the area shown in Figure 13c. (b) Time series at the center of the deformation signal. (c) Data, source model synthetic interferograms, and residuals. (d) N-S and $\mathrm{W}-\mathrm{E}$ profiles of data and models.

hydrologic deformation than volcanic deformation. Indeed, similar signal patterns are commonly distributed over the entire area of the image, with no preferential association with volcanic areas. Therefore, we do not interpret these signals as magmatic or even hydrothermal processes.

\subsubsection{Volcanic Activity Without Measurable Deformation}

[23] Several volcanoes on Java had eruptive activity during and after the study period (Table 2), but we did not detect significant deformation associated with any of them (except for Slamet and possibly Kelut). Semeru has been erupting almost constantly since 1967, including during our study period [Smithsonian Institution, 2009b]. Its lack of deformation may reflect an open-conduit steady state system in which magma chamber pressure and volume remains fairly static. The best-studied volcano with similar behavior, Stromboli, is an example of an open-conduit system [Giberti et al., 1992; Harris and Stevenson, 1997] which also exhibits very little surface deformation [Bonaccorso et al., 2009]. The isolated eruptions of Kelut [Smithsonian Institution, 2008a, 2008b] and Raung [Smithsonian Institution, 2007, 2008c], may have been sourced from magma bodies too small, too shallow, or too deep to produce noticeable signals when they erupted and emptied (none of these were major eruptions). The emplacement of a magma body may precede eruption by months or years, so we would not necessarily expect to detect deformation related to eruptions that occurred after our observation period ended, such as the 2009 phreatic explosions at the Dieng Volcanic Complex [Smithsonian Institution, 2009c, 2009d] and the late 2010 significant eruptions of Merapi and Bromo. A longer time period of continuous observation, encompassing a greater number and variety 
(A)

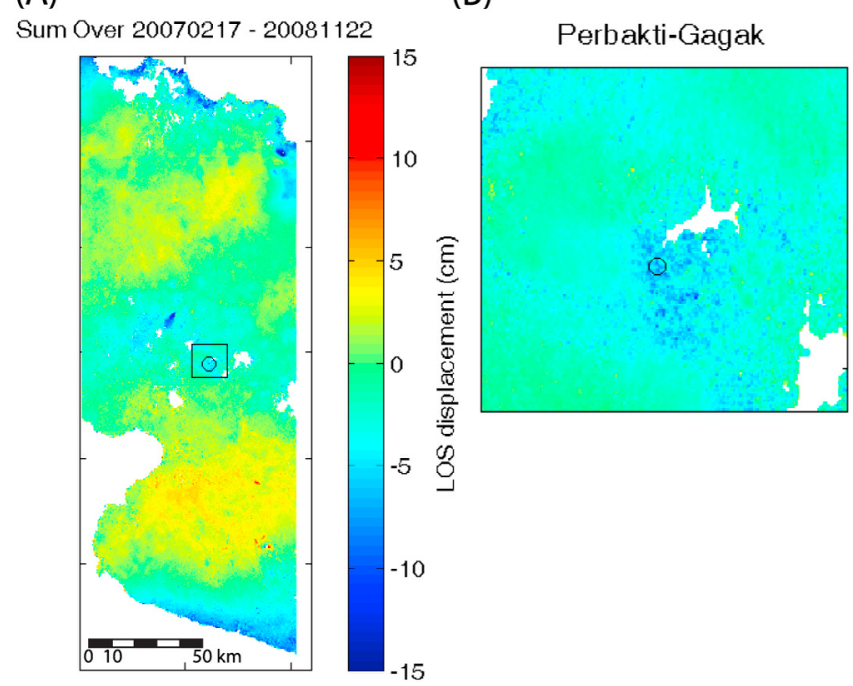

(C)

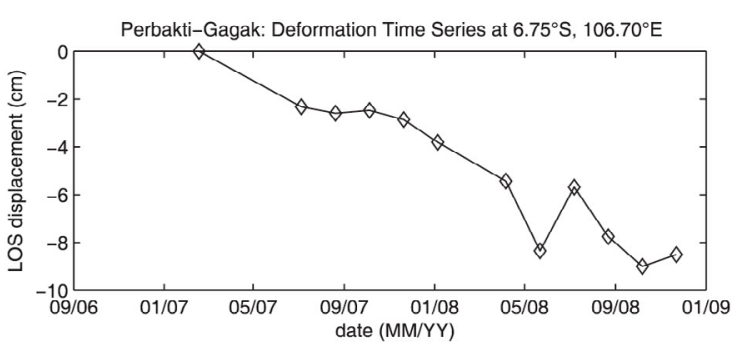

Figure 14. Deformation of Perbakti-Gagak. (a) Sum of all time steps (dates are in YYYYMMDD format) for track 438 (see Figure 1 for corresponding geographic footprint). Box shows area of Figure 14b; black circle shows location of Perbakti-Gagak volcano. (b) Detail of Perbakti-Gagak area; black circle centered on time series point. (c) Time series of Perbakti-Gagak showing $\sim 5 \mathrm{~cm} / \mathrm{yr}$ LOS change consistent with subsidence.

of eruptions, would be required to elucidate the relationship between detectable deformation and eruptions.

\subsection{Hydrologic and Other Deformation}

[24] Every time series sum that we produced includes scattered areas which receded from the satellite, consistent with subsidence. Areas moving toward the satellite, consistent with uplift, also exist but are less ubiquitous and generally have lower magnitudes of deformation. The time series for areas of subsidence typically show constant deformation with LOS change rates on the order of $\sim 5 \mathrm{~cm} / \mathrm{yr}$. This type of deformation is almost certainly due to hydrologic processes, particularly groundwater extraction (or irrigation/injection for uplifted areas).
(A)

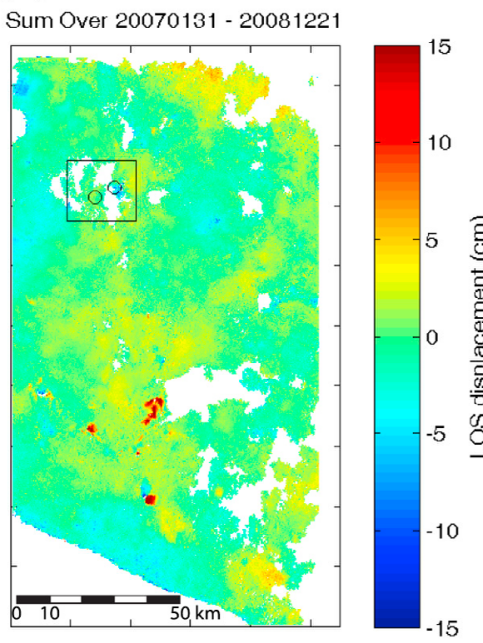

(B)

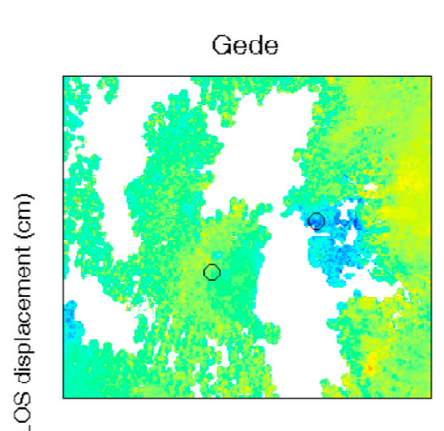

(C)

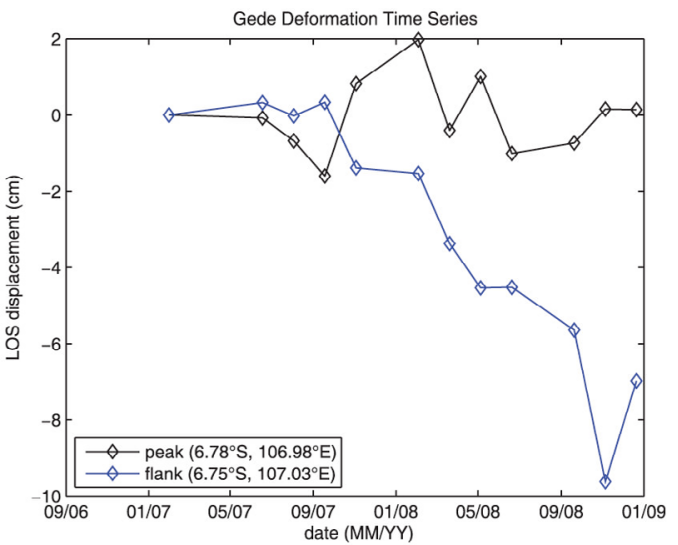

Figure 15. Deformation of Gede. (a) Sum of all time steps (dates are in YYYYMMDD format) for track 437 (see Figure 1 for corresponding geographic footprint). Box shows area of Figure 15b; black circles show location of Gede peak (left) and flank deformation area (right). (b) Detail of Gede area; black circles centered on time series points. (c) Time series showing essentially zero deformation at Gede's peak and $\sim 6 \mathrm{~cm} / \mathrm{yr}$ LOS change consistent with subsidence (starting Sep 2007) at the flank. 
(A)

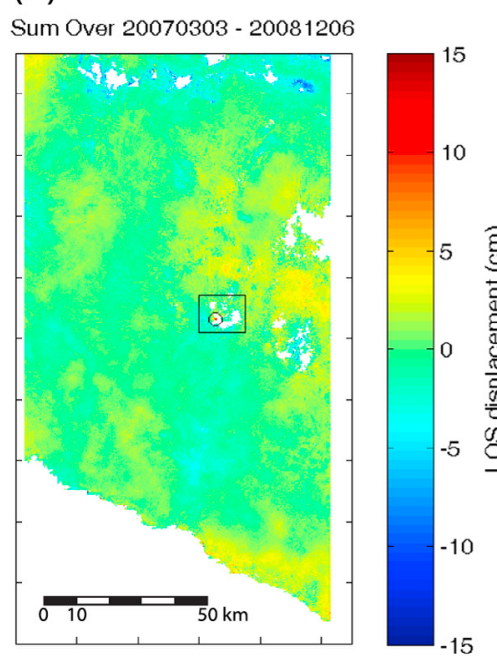

(B)

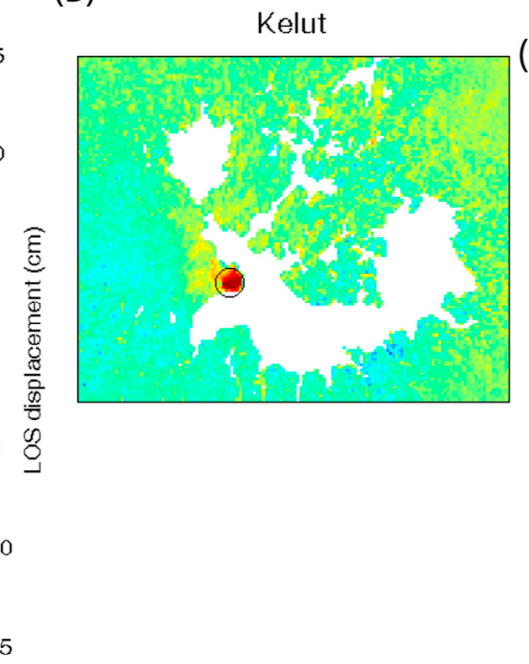

(C)

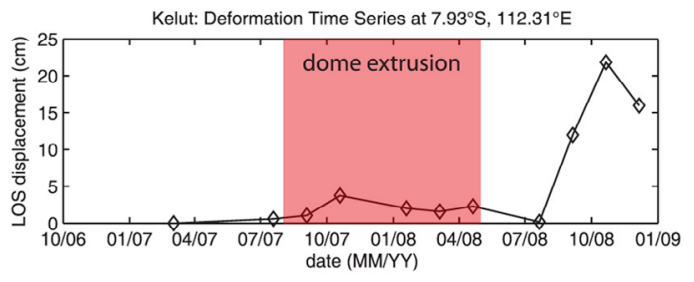

Figure 16. Deformation of Kelut. (a) Sum of all time steps (dates are in YYYYMMDD format) for track 428 (see Figure 1 for corresponding geographic footprint). Box shows area of Figure 16b; black circle shows location of Kelut volcano. (b) Detail of Kelut area; black circle centered on time series point. (c) Time series of Kelut showing potential $15 \mathrm{~cm}$ LOS change consistent with uplift. Period of observed lava dome extrusion is shown in red.

The most spectacular example is the Bandung Basin, an elevated valley surrounded by volcanic mountains which has rates of LOS change up to $17 \mathrm{~cm} / \mathrm{yr}$ (Figure 17), suggesting extreme subsidence rates up to $21 \mathrm{~cm} / \mathrm{yr}$ if we assume motion is predominantly vertical. Campaign GPS measurements have confirmed that the deformation is primarily vertical subsidence, and are in agreement with the rates we measure [Abidin et al., 2009a]. This deformation is surely affecting the surface landscape, perhaps producing shallow faulting and fissures similar to those formed due to groundwater extraction in other regions such as the San Joaquin Valley of California [e.g., Poland, 1981; Holzer, 1984]. (Some incipient ground disruption in the area was documented by Abidin et al. [2009a].) A few other areas on Java have similarly high subsidence rates (see auxiliary material), but none are as large as the Bandung Basin.

[25] One other source of deformation that is worth noting is the mud volcano "Lusi" in east Java, which began erupting on May 29, 2006. Perhaps triggered by a gas exploration well, the eruption is ongoing and has created a local disaster area by burying many villages in warm mud. The evacuation of mud from a layer $\sim 2.8 \mathrm{~km}$ deep is causing the overlying area to subside [Davies et al., 2007]. It is important to monitor deformation associated with the mud volcano, since the evacuation of material may eventually lead to a caldera collapse, expanding the disaster area far beyond the area currently flooded with mud.
This deformation is easily seen in our data, which show two lobes of subsidence and an area of uplift (Figures 18a and 18b), coincident with the three deformation areas identified by Abidin et al. [2009b].

[26] The subsidence pattern in the lobe immediately beneath the mud volcano is complex, with spots of localized deformation exhibiting very rapid subsidence (up to $120 \mathrm{~cm} / \mathrm{yr}$ LOS change) during late 2006 to early 2007, but later leveling out to lower rates of $8-10 \mathrm{~cm} / \mathrm{yr}$, which persisted throughout most of the center of the deformation lobe during our study period (Figure 18c). For purely vertical deformation, these rates would correspond

Table 2. Activity of Javanese Volcanoes During 2007-2010

\begin{tabular}{lll}
\hline \multicolumn{1}{c}{ Name } & \multicolumn{1}{c}{ Activity } & \multicolumn{1}{c}{ Date(s) } \\
\hline $\begin{array}{l}\text { Slamet } \\
\text { Dieng Volc. }\end{array}$ & eruption & April-June 2009 \\
Complex & phreatic & January and \\
Merapi & eruptions & September 2009 \\
& & March 2006- \\
& ash plumes & May 2007 \\
& & August 2007 and \\
& eruption & May 2008 \\
& & September- \\
& dome extrusion & December 2010 \\
Kelut & & Aust 2007- \\
& eruptions & continuous \\
Semeru & eruption & November- \\
Bromo (Tengger & & December 2010 \\
Caldera) & ash plumes & August 2007 and \\
Raung & & June 2008 \\
& &
\end{tabular}


(A)

\section{Sum Over 20070301 - 20081204}

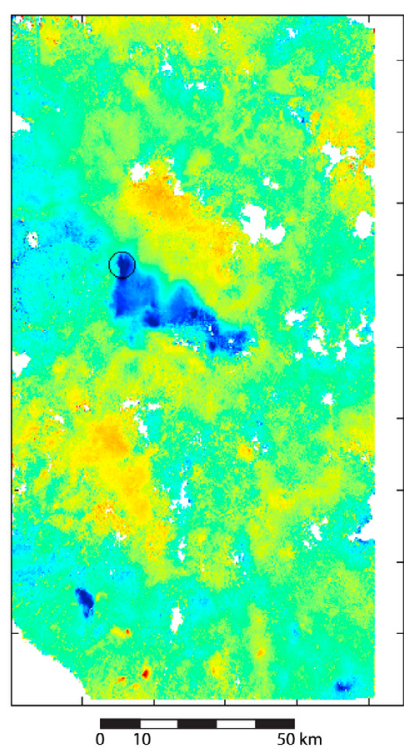

(B)

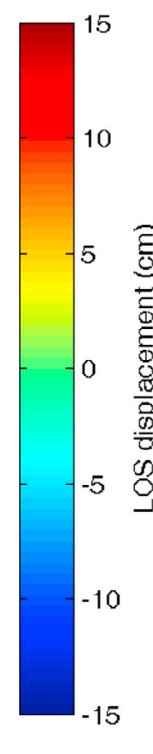

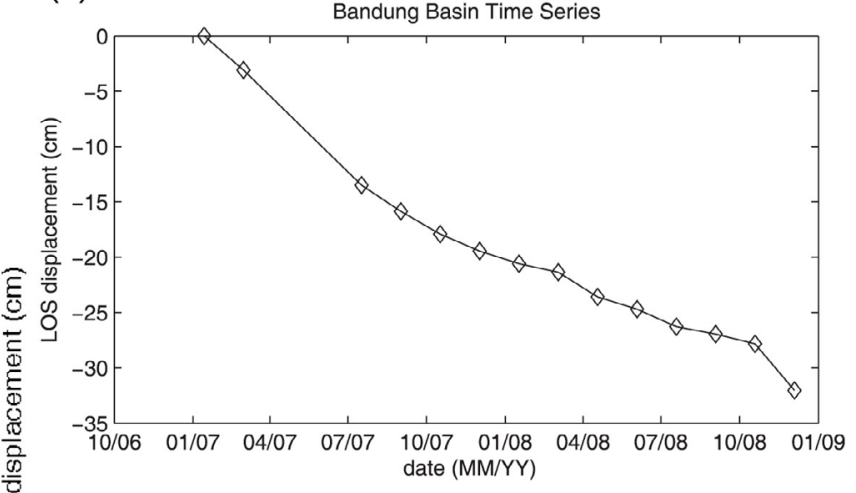

Figure 17. Deformation of the Bandung basin. (a) Sum of all time steps (dates are in YYYYMMDD format) for track 436 (see Figure 1 for corresponding geographic footprint). Black circle is centered on time series point shown in Figure 17b. (b) Time series of northwest Bandung basin showing $\sim 17 \mathrm{~cm} / \mathrm{yr}$ LOS change consistent with subsidence.

to $150 \mathrm{~cm} / \mathrm{yr}$ and $10-12 \mathrm{~cm} / \mathrm{yr}$ of subsidence. In contrast, ground-based campaign GPS measurements yielded significantly higher maximum subsidence rates, decreasing from $3 \mathrm{~mm} /$ day to $1 \mathrm{~mm}$ /day during 2007 [Abidin et al., 2009b]. This discrepancy likely occurs because the areas of greatest subsidence are decorrelated in our interferograms, due to the alteration of the surface by continued eruption of mud.

[27] The lobe of deformation northwest of Lusi has a smooth deformation pattern, with a maximum LOS change rate of $9 \mathrm{~cm} / \mathrm{yr}$. Abidin et al. [2009b] interpreted this lobe of deformation as being related to gas extraction in the Wunut gas field and having no relation to the eruption of mud at Lusi; however, the coincidence in timing and the similarity of the deformation rates suggests otherwise. It is plausible that the Lusi plumbing system is drawing mud from more than one region of the source layer. The area of range decrease northeast of Lusi has lower deformation rates, with a fairly constant maximum LOS change rate of $3 \mathrm{~cm} / \mathrm{yr}$. This would correspond to a pure uplift rate of $3.5 \mathrm{~cm} / \mathrm{yr}$, whereas the uplift rate reported by Abidin et al. [2009b] is about ten times higher. However, the exact locations and time periods used by Abidin et al. to determine their rate are unclear, so it is difficult to make a direct comparison. Modeling of PALSAR data suggests that this range decrease may primarily reflect horizontal deforma- tion due to contraction of the mud source area [Fukushima et al., 2009]. The Watukosek fault, which was reactivated following the eruption, may be accommodating this deformation [Abidin et al., 2009b].

\section{Conclusions}

[28] From a geodetic imaging perspective, we can conclude that monitoring volcanic deformation in Java with L-band interferometry requires shorttime-interval pairs with moderate to short Bperp in order to minimize decorrelation. This strategy would likely also be necessary in other heavily vegetated tropical areas. Our time series approach has the additional benefit of resolving the time scale of deformation events and changes in deformation rates over time. Applying a tropostatic phase correction [Lin et al., 2010] helps to reduce atmospheric propagation delay noise in the data, but the remaining noise levels limit the detection of smallmagnitude deformation. In general, our method cannot detect LOS deformation smaller than $\sim 5 \mathrm{~cm}$, and temporary deformation on time scales shorter than $\sim 6$ months will likewise be masked by noise.

[29] Our observations corroborate earlier studies which demonstrated that the relationship between detectable volcanic deformation and eruptive activity 
(A)

\section{Sum Over $20061230-20081004$}

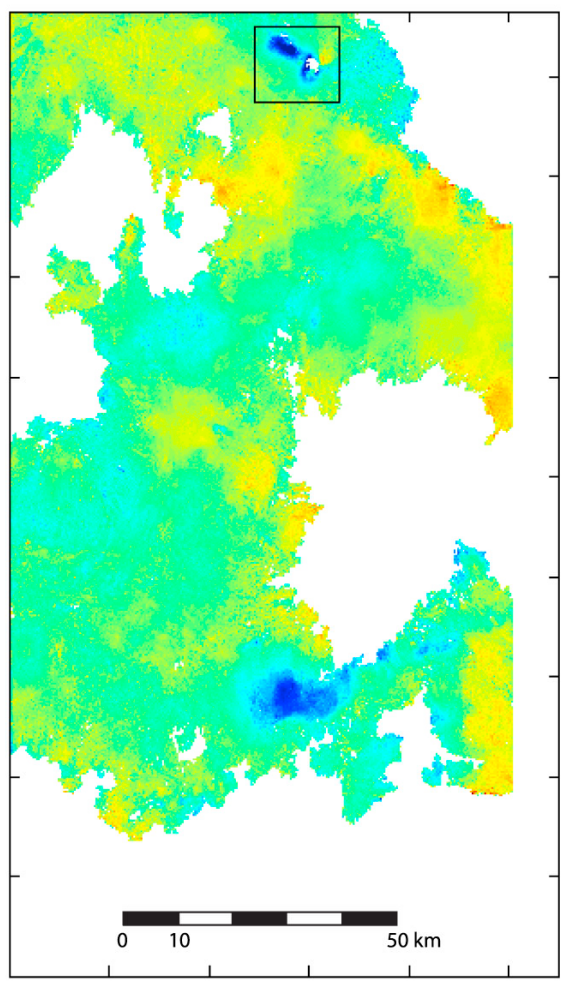

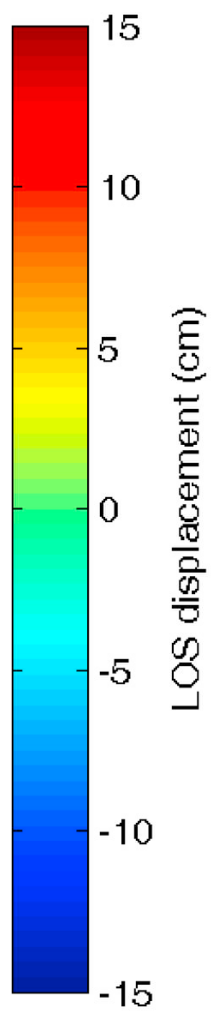

(B)

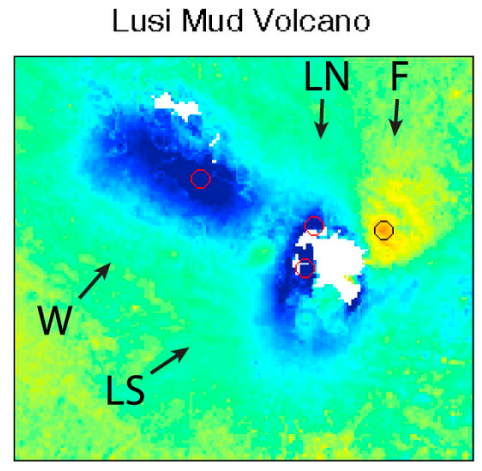

(C)

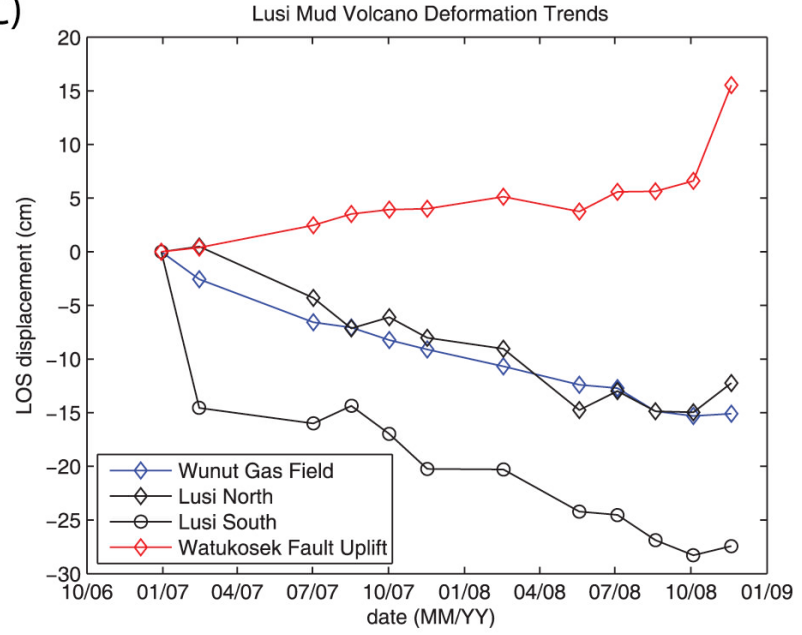

Figure 18. Deformation of Lusi mud volcano. (a) Sum of time steps (dates are in YYYYMMDD format) for track 427 (see Figure 1 for corresponding geographic footprint). Box shows area of Figure 18b. (b) Detail of Lusi area. Circles are centered on time series points shown in Figure 18c, where W is the Wunut gas field, LN is Lusi North, LS is Lusi South, and F is the Watukosek Fault Uplift. (c) Time series of Lusi.

is far from simple [Pritchard and Simons, 2004b; Fournier et al., 2010]. During our two-year study period, we observed deformation due to one deep intrusion that does not appear linked to any eruptive activity (Lamongan), and one shallow intrusion that may have later erupted (Slamet). We did not observe significant deformation associated with any of the volcanic activity that occurred during the study period. However, any volcanoes which are currently deforming or recently deformed (such as Lamongan) are good candidates for targeted ground-based monitoring.

[30] Our two-year time window is clearly too short to make any statistically significant estimates of the frequency of magmatic intrusions or the percentage of intrusions which later erupt. To better understand the relationship between intrusion and eruption, this study should be extended to cover a longer time period encompassing a larger number and variety of eruptions. Extending this study has the potential to reveal the typical delay between magma chamber emplacement and eruption, relative frequency of intrusions and eruptions, and other aspects of volcanic behavior which are of great interest to volcano science and hazard mitigation.

[31] Our study demonstrates that L-band interferometry can be a valuable tool for regional volcanic (and hydrologic) deformation monitoring in heavily vegetated tropical areas which are poorly suited to the use of C-band InSAR. The strategy we have developed has the potential to be applied in many areas where volcanic monitoring is currently sparse, and should be of interest to volcanic hazard mitigation agencies as well as academic researchers.

\section{Acknowledgments}

[32] This paper was improved thanks to thoughtful reviews by Jeff Freymueller and Chris Newhall. We would also like to 
thank Chris Newhall, Simon Carn, and Surono for sharing their expertise regarding volcanic activity on Java, Yu-Nung Nina Lin and Chris DiCaprio for their assistance with InSAR processing techniques, Eric Fielding, Sang-Ho Yun, and Paul Rosen for their help with ROI_PAC, and Faria Chowdhury for developing a data management system for ROI_PAC. This study was supported in part by the Gordon and Betty Moore Foundation. This is Caltech Tectonics Observatory contribution 180 and SeismoLab contribution 10064.

\section{References}

Abidin, H. Z., H. Andreas, I. Gumilar, S. Wangsaatmaja, Y. Fukuda, and T. Deguchi (2009a), Land subsidence and groundwater extraction in Bandung Basin, in Trends and Sustainability of Groundwater in Highly Stressed Aquifers, edited by M. Taniguchi et al., IAHS Publ., 329, 145-156.

Abidin, H. Z., R. J. Davies, M. A. Kusuma, H. Andreas, and T. Deguchi (2009b), Subsidence and uplift of Sidoarjo (East Java) due to the eruption of the Lusi mud volcano (2006present), Environ. Geol., 57(4), 833-844, doi:10.1007/ s00254-008-1363-4.

Berardino, P., G. Fornaro, R. Lanari, and E. Sansosti (2002), A new algorithm for surface deformation monitoring based on Small Baseline Differential SAR Interferograms, IEEE Trans. Geosci. Remote Sens., 40(11), 2375-2383, doi:10.1109/ TGRS.2002.803792.

Bonaccorso, A., A. Bonforte, S. Gambino, M. Mattia, F. Guglielmino, G. Puglisi, and E. Boschi (2009), Insight on recent Stromboli eruption inferred from terrestrial and satellite ground deformation measurements, J. Volcanol. Geotherm. Res., 182(3-4), 172-181, doi:10.1016/j.jvolgeores. 2009.01.007.

Bürgmann, R., P. Rosen, and E. Fielding (2000), Synthetic aperture radar interferometry to measure Earth's surface topography and its deformation, Annu. Rev. Earth Planet. Sci., 28, 169-209, doi:10.1146/annurev.earth.28.1.169.

Carn, S. A. (2000), The Lamongan volcanic field, East Java, Indonesia; Physical volcanology, historic activity and hazards, J. Volcanol. Geotherm. Res., 95(1-4), 81-108, doi:10.1016/S0377-0273(99)00114-6.

Center for Volcanology and Geological Hazard Mitigation (CVGHM) (2005), Laporan kegempaan gunungapi Lamongan bulan Januari 2005, internal report, 7 pp., Bandung, Indonesia.

Davies, R. J., R. E. Swarbrick, R. J. Evans, and M. Huuse (2007), Birth of a mud volcano: East Java, 29 May 2006, GSA Today, 17(2), 4-9.

DiCaprio, C. J. (2010), Measuring and modeling viscoelastic relaxation of the lithosphere with application to the northern volcanic zone, Iceland, Ph.D. thesis, Calif. Inst. of Technol., Pasadena, Calif.

Fournier, T. J., M. E. Pritchard, and S. N. Riddick (2010), Duration, magnitude, and frequency of subaerial volcano deformation events; new results from Latin America using InSAR and a global synthesis, Geochem. Geophys. Geosyst., 11, Q01003, doi:10.1029/2009GC002558.

Fukushima, Y., J. Mori, M. Hashimoto, and Y. Kano (2009), Subsidence associated with the Lusi mud eruption, East Java, investigated by SAR interferometry, Mar. Pet. Geol., 26(9), 1740-1750, doi:10.1016/j.marpetgeo.2009.02.001.
Giberti, G., C. Jaupart, and G. Sartoris (1992), Steady-state operation of Stromboli volcano, Italy: Constraints on the feeding system, Bull. Volcanol., 54(7), 535-541, doi:10.1007/BF00569938.

Hanssen, R. F. (2001), Radar Interferometry: Data Interpretation and Error Analysis, 308 pp., Kluwer Acad., Dordrecht, Netherlands.

Harris, A. J. L., and D. S. Stevenson (1997), Magma budgets and steady-state activity of Vulcano and Stromboli, Geophys. Res. Lett., 24(9), 1043-1046, doi:10.1029/97GL00861.

Holzer, T. L. (1984), Ground failure induced by ground-water withdrawal from unconsolidated sediment, in Man-Induced Land Subsidence, Rev. Eng. Geol., vol. 6, pp. 67-105, Geol. Soc. Am., Boulder, Colo.

Lin, Y. N., M. Simons, E. Hetland, P. Muse, and C. DiCaprio (2010), A multiscale approach to estimating topographically correlated propogation delays in radar interferograms, Geochem. Geophys. Geosyst., 11(9), Q09002, doi:10.1029/ 2010GC003228.

Massonnet, D., and K. Feigl (1998), Radar interferometry and its application to changes in the earth's surface, Rev. Geophys., 36(4), 441-500, doi:10.1029/97RG03139.

Mogi, K. (1958), Relations between the eruptions of various volcanoes and the deformations of the ground surface around them, Bull. Earthquake Res. Inst. Univ. Tokyo, 36, 99-134.

Neumann van Padang, M. (1951a), Slamet, in Catalogue of the Active Volcanoes of the World Including Solfatara Fields: Part I. Indonesia, edited by International Volcanological Association, pp. 102-105, Int. Volcanol. Assoc., Naples, Italy.

Neumann van Padang, M. (1951b), Kiaraberes Gagak, in Catalogue of the Active Volcanoes of the World Including Solfatara Fields: Part I. Indonesia, edited by International Volcanological Association, pp. 66-68, Int. Volcanol. Assoc., Naples, Italy.

Neumann van Padang, M. (1951c), Gedeh, in Catalogue of the Active Volcanoes of the World Including Solfatara Fields: Part I. Indonesia, edited by International Volcanological Association, pp. 72-74, Int. Volcanol. Assoc., Naples, Italy.

Poland, J. F. (1981), Subsidence in United States due to ground water withdrawal, J. Irrig. Drain. Div. Am. Soc. Civ. Eng., 107(IR2), 115-135.

Pritchard, M. E., and M. Simons (2004a), Surveying volcanic arcs with satellite radar interferometry: The central Andes, Kamchatka, and beyond, GSA Today, 14(8), 4-11, doi:10.1130/1052-5173(2004)014<4:SVAWSR >2.0.CO;2.

Pritchard, M. E., and M. Simons (2004b), An InSAR-based survey of volcanic deformation in the central Andes, Geochem. Geophys. Geosyst., 5, Q02002, doi:10.1029/ 2003 GC000610.

Rosen, P. A., S. Hensley, H. A. Zebker, F. H. Webb, and E. J. Fielding (1996), Surface deformation and coherence measurements of Kilauea Volcano, Hawaii, from SIR-C radar interferometry, J. Geophys. Res., 101(E10), 23,109-23,125, doi:10.1029/96JE01459.

Rosen, P. A., S. Hensley, G. Peltzer, and M. Simons (2004), Updated repeat orbit interferometry package released, Eos Trans. $A G U, 85(5), 47$, doi:10.1029/2004EO050004.

Rosenqvist, A., M. Shimada, N. Ito, and M. Watanabe (2007), ALOS PALSAR: A pathfinder mission for global-scale monitoring of the environment, IEEE Trans. Geosci. Remote Sens., 45(11), 3307-3316, doi:10.1109/TGRS.2007.901027.

Simons, M., and P. Rosen (2007), Interferometric synthetic aperture radar geodesy, in Treatise on Geophysics, edited 
by G. Schubert, pp. 391-446, Elsevier, Amsterdam, doi:10.1016/B978-044452748-6.00059-6.

Smithsonian Institution (1985), Lamongan, Sci. Event Alert Network Bull., 10(10), Washington, D. C.

Smithsonian Institution (1988), Lamongan, Sci. Event Alert Network Bull., 13(2), Washington, D. C.

Smithsonian Institution (2007), Raung, Bull. Global Volcanism Network, 32(9), Washington, D. C.

Smithsonian Institution (2008a), Kelut, Bull. Global Volcanism Network, 33(3), Washington, D. C.

Smithsonian Institution (2008b), Kelut, Bull. Global Volcanism Network, 33(7), Washington D. C.

Smithsonian Institution (2008c), Raung, Bull. Global Volcanism Network, 33(6), Washington, D. C.
Smithsonian Institution (2009a), Slamet, Bull. Global Volcanism Network, 34(5), Washington, D. C.

Smithsonian Institution (2009b), Semeru, Bull. Global Volcanism Network, 34(5), Washington, D. C.

Smithsonian Institution (2009c), Dieng Volcanic Complex, Bull. Global Volcanism Network, 34(4), Washington, D. C.

Smithsonian Institution (2009d), Dieng Volcanic Complex, Bull. Global Volcanism Network, 34(8), Washington, D. C. Smithsonian Institution (2010), Slamet, Bull. Global Volcanism Network, 35(1), Washington, D. C.

Zebker, H., and J. Villasenor (1992), Decorrelation in interferometric radar echoes, IEEE Trans. Geosci. Remote Sens., 30(5), 950-959, doi:10.1109/36.175330. 